\title{
Algunos hallazgos votivos y suntuarios en hueso y marfil del yacimiento calcolítico de Valencina de la Concepción (Sevilla)
}

Some votive and sumptuous artefacts in bone and ivory on the Calcolithic site of Valencina de la Concepción (Sevilla)

\author{
CRISTINA CABRERA TARAVILLO ${ }^{1}$ \\ Universidad Autónoma de Madrid \\ cristina.cabrerat@estudiante.uam.es
}

Resumen: El yacimiento calcolítico de Valencina de la Concepción (Sevilla) presenta un abundante registro de materiales suntuosos y votivos elaborados en diferentes materias primas. El objetivo del presente trabajo ha sido recopilar algunos de los principales objetos realizados en hueso y marfil que desde el siglo xx se han ido publicando, para con ello facilitar su lectura y poner de relevancia algunas de las interpretaciones de este complejo asentamiento del Suroeste peninsular.

Palabras clave: Calcolítico, Valencina de la Concepción, arqueozoología, industria ósea, marfil.

Abstract: The Calcolithic site of Valencina de la Concepción (Sevilla) presents an abundant record of sumptuous and votive objects made from different raw materials. The aim of this paper is to gather some of the artefacts made in bone and ivory which have been published since the twentieth century, to try to understand and to highlight some of the interpretations of this complex site of peninsular Southwest.

Keywords: Calcolithic, Valencina de la Concepción, Archeozoology, bone artefacts, ivory.

\footnotetext{
${ }^{1}$ Becaria de Fomento a la Investigación para Estudios de Máster de la Universidad Autónoma de Madrid, Departamento de Prehistoria y Arqueología.
}

Recibido: 18 de octubre de 2016; aceptado: 15 de marzo de 2017; publicado: 21 de septiembre de 2017. Revista Historia Autónoma, 11 (2017), pp. 15-42. 
Introducción

A pocos kilómetros de la actual ciudad de Sevilla se sitúa el conjunto arqueológico de Valencina de la Concepción, uno de los poblados de recintos de fosos más importantes del Calcolítico de la Península Ibérica (fig. 1). Con una extensión de unas 470 hectáreas ${ }^{2}$, este asentamiento incluye algunos de los más imponentes monumentos megalíticos del registro peninsular. Debido a su magnitud, la comunidad que poblaba este yacimiento pudo tener una significativa importancia demográfica, social y económica en toda la región de Andalucía occidental.

Figura 1: Propuesta de la extensión del poblado calcolítico de Valencina (en rojo) y su necrópolis (en verde).

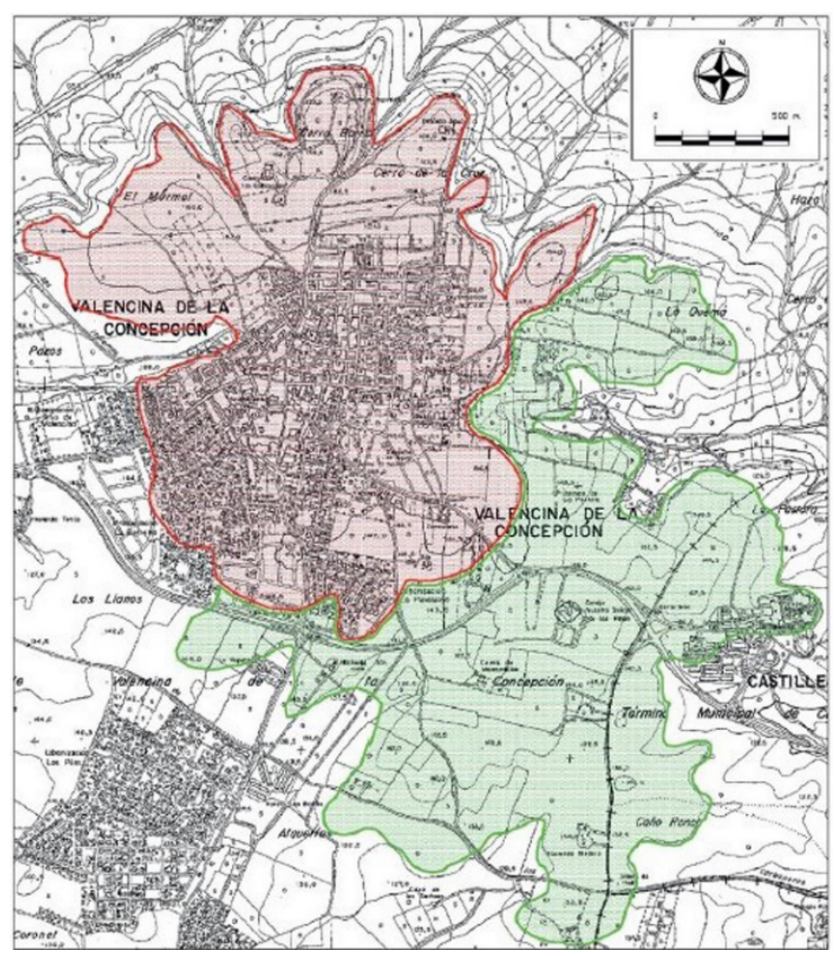

Fuente: Vargas Jiménez, José Manuel, Carta Arqueológica Municipal de Valencina de la Concepción, Sevilla, Junta de Andalucía, 2004, figura 10.

Desde su descubrimiento, gracias al tholos de La Pastora a finales del siglo XIX, le siguieron otros impresionantes hallazgos, como los tholoi de Matarrubilla y Montelirio, así como de otras tantas estructuras, como centenares de hoyos y tramos de fosos de diferente profundidad y morfología. Pero como consecuencia a que buena parte del yacimiento se encuentra bajo la actual población que recibe el mismo nombre, ha sido un área excavada de una manera

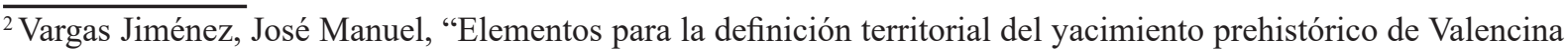
de la Concepción (Sevilla)", en Spal. Revista de Prehistoria y Arqueología, 12 (2004), p. 141. DOI: https://doi. org/10.12795/spal.2003.i12.06.
} 
muy fragmentaria debido a las necesidades urbanísticas. Como resultado, la situación actual del estudio científico se ve protagonizada por la contradicción que resulta haber abordado un registro arqueológico muy amplio y complejo mediante excavaciones antiguas y excavaciones de urgencia, muchas de ellas carentes de medios y especialización. En los últimos años de nuestra década se ha producido un gran esfuerzo en una puesta al día, al igual que un incremento de la actividad investigadora ${ }^{3}$, con la aparición de sucesivas publicaciones que han comenzado a aportar resultados científicos basados en la naturaleza del territorio, paleoambiente, estudios antropológicos y arqueozoológicos, secuencias ocupacionales, análisis espaciales, estrategias de subsistencia y de producción de este gran asentamiento prehistórico.

A su gran magnitud se le suma una acentuada complejidad estructural, causada por la presencia de abundantes y variados elementos, como los citados fosos, fosas, grandes sepulcros, pozos cilíndricos o posibles áreas "industriales", que poseen una indefinición temporal que obstaculizan el conocimiento del yacimiento. A grandes rasgos, Valencina se ha interpretado desde una perspectiva marxista como un gran poblado de fosos ocupado por poblaciones campesinas sedentarias, que según la visión de algunos autores estaría ordenado de manera funcional ${ }^{4}$, donde se encontraría un "área habitacional" dedicada a la residencia y a la producción, el "área intermedia" dedicada a las actividades económicas y un "área de necrópolis" donde se localizan una gran variabilidad de estructuras funerarias, materiales y contenidos, así como número de individuos y ajuares, que plantean intencionalidades de carácter social claramente diferenciadoras entre unos y otros ${ }^{5}$ - pese a existir enterramientos en las otras dos áreas-.

Respecto a su ubicación, se encuentra localizado sobre la zona norte de la plataforma elevada de la comarca de El Aljarafe, en el margen derecho del río Guadalquivir. Cada vez se va teniendo más información acerca del entorno antiguo que podía poseer la calcolítica Valencina, donde destacamos su paleotopografía. Hace unos 6000 años el nivel del mar era unos 2 m más alto que en la actualidad lo que, unido a la menor presencia de sedimentos aluviales en el Bajo Guadalquivir y a la inexistencia de ciertas barreras naturales que en nuestros días amortiguan la penetración de aguas marinas hacia el interior, provocaron la incursión del mar casi hasta el actual emplazamiento de Sevilla, lo que modificó las condiciones de vida de las comunidades pretéritas que habitaban ese entorno ${ }^{6}$.

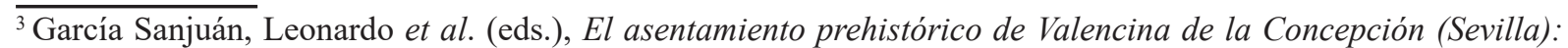
Investigación y Tutela en el 150 Aniversario del Descubrimiento de La Pastora, Sevilla, Universidad de Sevilla, 2013.

${ }^{4}$ Mejías García, Juan Carlos, “Análisis espacial en el asentamiento y necrópolis de Valencina (Sevilla): patrones de distribución y sectorización", en Actas del VI Encuentro de Arqueología del Suroeste Peninsular, Villafranca de los Barros, Ayuntamiento de Villafranca de los Barros, 2013, pp. 465-500; Mejías García, Juan Carlos et al., "Análisis del modelo de organización espacial de la necrópolis de Valencina. La complejidad social a debate", en Actas del congreso Arqueologia de Transiçao: o mundo Funerário, pp. 52-70. «http://www.chaia.uevora.pt/ uploads/pdfs/1c2ad7de950d111c7744fc6e00c37e14728b0efc.pdf» [consultado el 16 de octubre de 2016].

${ }^{5}$ Cruz-Auñón Briones, Rosario y Juan Carlos Mejías García, "Diveridad de prácticas funerarias e identidades en el asentamiento de Valencina de la Concepción (Sevilla)", en García Sanjuán, Leonardo et al. (eds.), El asentamiento prehistórico... op. cit., pp. 175-200.

${ }^{6}$ Márquez Romero, José Enrique y Víctor Jiménez Jáimez, Recintos de fosos. Genealogía y significado de una tradición en la Prehistoria del suroeste de la Península Ibérica (IV-III milenios AC), Málaga, Universidad de Málaga, 2010, p. 117.
} 
Así, la disponibilidad de recursos de esta privilegiada situación ha permitido una intensa ocupación poblacional desde finales del IV hasta mediados del III milenio a.n.e., donde muestra una menor densidad a partir de entonces. Pero el yacimiento aún no se abandonaría ya que, según algunas aportaciones ${ }^{7}$, las evidencias que demuestran la ocupación de Valencina durante la Edad del Hierro son numerosas, algo que resulta congruente con el notable poblamiento que toda la cornisa de El Aljarafe tuvo en la primera mitad del I milenio a.n.e. y que seguiría teniendo en época romana -el sitio de El Carambolo se encuentra a $5 \mathrm{~km}$ al Sureste de Valencina e Itálica se extiende a $6 \mathrm{~km}$ al Noreste-, lo cual añade profundidad temporal y amplitud paisajística al valor de este yacimiento como bien patrimonial.

Dentro de este excepcional contexto, nos disponemos a realizar una aproximación al "laboratorio" de transformación social y procesos de dominación territorial que supone el yacimiento calcolítico de Valencina de la Concepción, en cuanto a sus relaciones centroperiferia a través de la producción y la circulación de productos artesanales elaborados con materias primas exóticas y mediante sus ricos objetos votivos y suntuarios en hueso y marfil. El origen de este ensayo se fundamenta en el denominado Trabajo de Fin de Grado ${ }^{8}$ que, sin ser un trabajo de investigación, se ha encargado de recopilar estos objetos, prestando especial atención a los recientes del Sector PP4-Montelirio ya que ponen de manifiesto la importancia de la artesanía del marfil en términos comerciales, sociales e ideológicos. El concepto de expresión, comunicación y transmisión de mensajes que tienen los diferentes grupos sociales en determinados ámbitos espacio-temporales, se ve reflejado a través de sus recursos materiales; un hecho que nos va a permitir informarnos sobre sus estrategias sociales o relaciones territoriales. Un proceso que hace necesaria su contextualización y el estudio de los objetos para no recaer en la simplicidad, sino acercarnos a la compresión de la ideología social materializada por estos grupos prehistóricos complejos.

\section{Nociones previas en torno a los ídolos calcolíticos}

\section{1 ¿Qué entendemos por ídolo calcolítico?}

Una vez que hemos contextualizado sucintamente el contexto en que fueron hallados los materiales que vamos a tratar, debemos recapitular qué sabemos acerca de los ídolos enmarcados

\footnotetext{
${ }^{7}$ García Sanjuán, Leonardo, "El asentamiento de la Edad del Cobre de Valencina de la Concepción: estado actual de la investigación, debates y perspectivas", en García Sanjuán, Leonardo et al. (eds.), El asentamiento prehistórico... op. cit., p. 30.

${ }^{8}$ Leído en mayo de 2016 en el Departamento de Prehistoria y Arqueología de la Universidad Autónoma de Madrid.
} 
en el Calcolítico del Suroeste. Desde que comenzó su estudio, se identificaron muchos objetos de los que no se conocía su función o resultaban extraños en el habitual conjunto arqueológico conocido, empleando siempre el apelativo de "ritual". Los primeros estudios sobre este tipo de piezas, principalmente en el área del Sureste, fueron llevados a cabo por Luis Siret que, pese a no ser su objetivo principal de estudio, se interesó por el origen de sus ornamentaciones, su significado y elaboración ${ }^{9}$.

Muchos años después, María José Almagro ${ }^{10}$ realizó una recopilación de los ídolos conocidos hasta entonces, organizándolos en una tipología con posibles interpretaciones y elaborando en un extenso inventario. Este catálogo es, hasta la fecha, uno de los estudios peninsulares más completos sobre los ídolos calcolíticos, intentando clasificarlos y ofreciendo interpretaciones, algunas de ellas ya superadas, gracias a nuevos hallazgos y análisis arqueométricos.

Si intentamos definir qué es un ídolo, la mayoría de los autores que han abordado el tema no convergen en una idea común. Según el Diccionario de Prehistoria, el término ídolo define a una

\footnotetext{
"figura humana o animal realizada en barro, piedra, hueso o metal, etc., que suele representarse más o menos estilizada y es característica de los contextos culturales del Neolítico y Calcolítico. Los del occidente europeo, vinculados a enterramientos dolménicos, son más sumarios, realizándose sobre plaquetas de piedra decoradas más o menos profusamente, a veces con forma de sandalia, cayado o sobre falanges, a los que solamente se les diferencian los ojos (ídolos oculados)"'11.
}

La misma complejidad que tienen los autores al intentar definirlos, la encuentran al estudiarlos. En la actualidad, y gracias a los nuevos avances tecnológicos, se están empezando a desentramar algunas cuestiones referidas a estos objetos simbólicos, principalmente otorgándoles utilidades más prácticas. Pese a que todavía quedan muchas incógnitas sobre estos materiales y que la utilización del término "ídolo" es menor, los investigadores están intentando aproximarse al objetivo de comprender el papel que desempeñaban estas representaciones. Estas se entienden como materializaciones de la ideología social y deben ser contextualizadas y entender su variabilidad estilística en diferentes áreas geográficas, además de ponerlas en relación con las estructuras sociales y sus dinámicas. Por tanto, definimos "ídolos" a aquellos materiales que nos permiten reconocer formalmente a unos determinados objetos realizados sobre distintos soportes y que poseen una serie de representaciones características, y que sin

\footnotetext{
${ }^{9}$ Maicas Ramos, Ruth, "Los ojos que todo lo ven: oculados del Sureste”, en Maricas Ramos, Ruth et al. (coords.), Los ojos que nunca se cierran. Ídolos en las primeras sociedades campesinas, Madrid, Ministerio de Cultura, Museo Arqueológico Nacional, 2010, p. 116.

${ }^{10}$ Almagro Gorbea, María José, Los ídolos del Bronce I Hispánico, Madrid, Consejo Superior de Investigaciones Científicas, Instituto de Historia, 1973.

${ }^{11}$ Menéndez Fernández, Mario et al., Diccionario de Prehistoria, Madrid, Alianza Editorial, 1997, pp. 208-209.
} 
entrar en interpretaciones u otras discusiones, han formado parte del imaginario colectivo de las sociedades prehistóricas peninsulares ${ }^{12}$.

\subsection{Características generales sobre las materias primas y técnicas decorativas de los ídolos calcolíticos sobre hueso y marfil}

Los estudios sobre las técnicas decorativas de estas piezas están faltos de investigaciones experimentales y analíticas ${ }^{13}$, por lo que dificulta determinar con precisión las técnicas empleadas para la decoración de la mayor parte de ellos. Según Pascual, centrado en la zona valenciana, destaca el papel de tres técnicas: el grabado, la pintura y una combinación de $\operatorname{ambas}^{14}$. El grabado estaría realizado directamente sobre el soporte mediante incisión a diferentes profundidades, según se quiera perfilar, marcar o rayar la pieza. La pintura estaría realizada con coloraciones oscuras - rojos y negros- y tendría dos variantes diferentes, una pintura monocroma más habitual y otra bicroma ${ }^{15}$. Parece que algunas técnicas decorativas debieron ser bastante sofisticadas como propone Luis Siret en alguno de sus cuadernos. Destaca el procedimiento decorativo especial en un ejemplar de un ídolo en hueso largo de Almizaraque; que por medio de la aplicación de un engobe en superficie, compuesto supuestamente por una mezcla de resina y cera, se trazaba un dibujo con una punta hasta penetrar en la superficie del hueso para posteriormente sumergirlo en un líquido corrosivo que actuaba sobre las partes dibujadas, reservando las que están cubiertas por el engobe ${ }^{16}$.

Si sobre las técnicas decorativas el conocimiento es más bien escaso, sobre la preparación de la materia prima todavía lo es más. La morfología que presentan la mayoría de los ídolos viene impuesta por el propio soporte que, en ocasiones, es sometido a modificaciones que alteran su forma anatómica natural como la eliminación de una de las epífisis de huesos largos, el abrasionado, el vaciado del tejido esponjoso, la perforación... en general, serían posibles la mayoría de conceptos definidos por Maicas en su estudio sobre la industria ósea de la Cuenca del Vera ${ }^{17}$.

\footnotetext{
${ }^{12}$ Hurtado Pérez, Víctor, "Representaciones simbólicas, sitios, contextos e identidades territoriales en el Suroeste peninsular", en Maicas Ramos, Ruth et al. (coords.), Los ojos que nunca se cierran: Ídolos en las primeras sociedades campesinas, Madrid, Ministerio de Cultura, Museo Arqueológico Nacional, 2010, p. 138.

${ }^{13}$ Pascual Benito, Josep Lluís, "Ídolos oculados sobre huesos largos en las cuencas del Júcar y del Segura", en Maicas Ramos, Ruth et al. (coords.), Los ojos que nunca... op. cit., p. 93

${ }^{14}$ Íbidem, pp. 93-35.

${ }^{15}$ En los ídolos de Ereta del Pedregal se observa el empleo de dos tipos de colorante, una base de pintura blanca sobre la que se aplicó otra marrón. Íbidem, p. 94.

${ }^{16}$ Íbidem, p. 94.

${ }^{17}$ Maicas Ramos, Ruth, Industria ósea y funcionalidad: Neolítico y Calcolítico en la cuenca de Vera (Almería), Madrid, Consejo Superior de Investigaciones Científicas, Instituto de Historia, 2007, pp. 38-39.
} 


\section{Tipos e interpretaciones de los ídolos sobre materia orgánica en Valencina}

Junto con el estudio realizado por el matrimonio Leisner ${ }^{18}$, la catalogación clásica para este grupo de materiales es la de María José Almagro, citada en la mayoría de las investigaciones y que ha servido a muchos autores para clasificar algunas de las piezas aquí descritas ${ }^{19}$. En este inventario se hace alusión a todas las piezas peninsulares hasta el momento encontradas, lo que ha hecho observar a varios autores que la temática general de estas representaciones son los oculados y los antropomorfos (fig. 2). Es decir, obtenemos una serie de piezas que, variando su morfología y soportes, nos aportarían un mundo simbólico e ideológico común en todo el panorama peninsular desde finales del IV milenio pasando por todo III milenio a.n.e. ${ }^{20}$.

Figura 2: Tipología de ídolos calcolíticos en diferentes materias primas realizada por Víctor Hurtado.

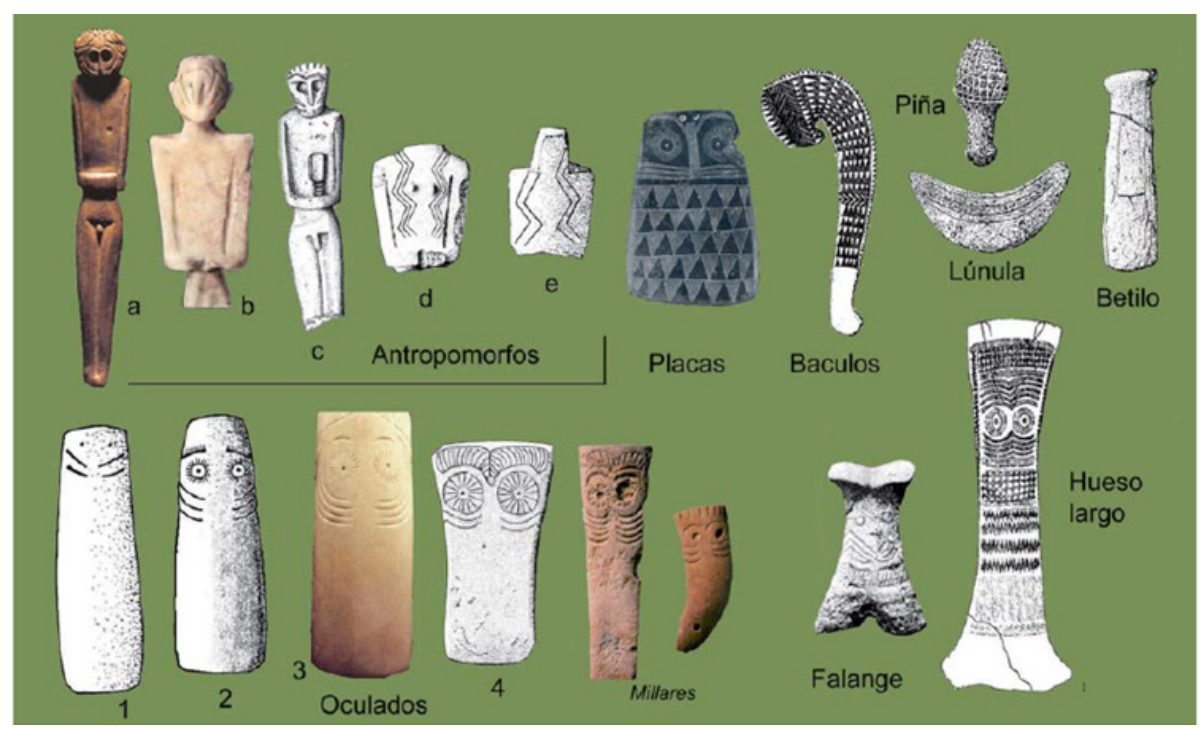

Fuente: Hurtado Pérez, Víctor, “Ídolos, estilos y...”op. cit., lámina 1.

Aceptando esta premisa temática, nos disponemos a hacer una enumeración de la tipología de estos ídolos según su manifestación oculada o antropomorfa en el yacimiento calcolítico de Valencina, pese a que muchos antropomorfos poseen elementos oculados y que a muchos oculados se les ha querido dar una morfología antropomorfa ${ }^{21}$.

\footnotetext{
${ }^{18}$ Leisner, Georg y Vera Leisner, A cultura eneolitica do Sul da Espanha e suas relaçoes com Portugal, Lisboa, Associaçao dos Arqueólogos Portuguêses, 1945.

${ }^{19}$ Fernández Gómez, Fernando y Diego Oliva Alonso, "Ídolos calcolíticos del Cerro de la Cabeza (Valencina de la Concepción, Sevilla)", en Madrider Mitteilungen, 21 (1980), pp. 20-24.

${ }^{20}$ Hurtado Pérez, Víctor, "Ídolos, estilos y territorios de los primeros campesinos en el sur peninsular", en Cacho Quesada, Carmen et al. (coords.), Acercándonos al pasado. Prehistoria en 4 Actos, Madrid, Ministerio de Cultura. Museos Estatales, Museo Arqueológico Nacional, Consejo Superior de Investigaciones Científicas, 2008, p. 3.

${ }^{21}$ Bécares, Julián, "Uniformidad conceptual en los ídolos del Calcolítico peninsular”, en Zephyrus, 43 (1990), pp. $87-94$.
} 


\section{1 Ídolos antropomorfos sobre hueso y marfil}

El tipo de ídolo denominado antropomorfo, que tiene diversas acepciones según la actual bibliografía arqueológica española, se identifica con varios tipos de objetos que tienen ciertos rasgos o similitudes con la forma humana. Según varios autores las adscriben a un tipo determinado, como María José Almagro denominándolos “ídolos antropomórficos” con dos subtipos $^{22}$.

A grandes rasgos podemos definir a estos ídolos como esculturillas de perfil aplanado en el que se representa el cuerpo humano completo en posición hierática, habitualmente de pie y con los brazos en la cintura. En ellas se puede distinguir las partes fundamentales del cuerpo humano como la cabeza, el tronco y las extremidades, aunque los elementos anatómicos no se indicarían con nitidez. En las representaciones faciales de estas figuras se sigue el esquema de ojos, cejas, tatuaje facial y peinado en zigzag. Se representan unos grandes ojos circulares rehundidos —que posiblemente se le incrustaran algún tipo de material que los hiciera más llamativos $^{23}$ - que son separados por una nariz en relieve que sobresale en el perfil por rebaje de las zonas laterales. También aquí figuran las cejas y las líneas del tatuaje facial. En lo que respecta al peinado, se inicia en la parte superior de la frente y continúa con líneas verticales en zigzag por el reverso hasta la mitad de la pieza que, en ocasiones, queda enmarcado por las incisiones que marcan los brazos. El tronco generalmente es trapezoidal o rectangular con un ligero estrechamiento hacia la cintura, y los brazos sólo se insinúan mediante acanaladuras verticales que crearían la ilusión de estar pegados al cuerpo. Los antebrazos suelen formar un ángulo acodado sobre la cintura, se presentan en una franja continua sin diferenciación entre ellos y sin mostrar las manos.

La mayoría de estas piezas suelen ser de pequeñas dimensiones, lo cual los convierte en objetos portables y sus contextos a veces resultan un tanto dudosos o incluso desconocidos. Tampoco existirían grandes diferencias tipológicas de estas piezas por regiones, ni una gran dispersión geográfica ya que principalmente estarían concentradas en el Sur peninsular; cambiando únicamente el soporte donde se realizan. Pese a la complejidad en la realización de estas piezas, es difícil aventurarse a considerar la posible especialización a tiempo completo de un grupo de individuos, aunque cabría la opción de admitir la existencia de una producción especializada realizada por expertos a tiempo parcial ${ }^{24}$. Las interpretaciones que sugiere Hurtado sobre estas piezas son de un uso no funerario debido a no hallarse, la mayoría, en contextos de esta índole ${ }^{25}$ - pese a que en asentamientos como La Cazuela en Granada si aparecen-.

\footnotetext{
${ }^{22}$ Almagro Gorbea, María José, Los ídolos del ... op. cit., pp. 247-255.

${ }^{23}$ Hurtado Pérez, Víctor, "Representaciones simbólicas..." op. cit., p.172.

${ }^{24}$ Íbidem, p. 176.

${ }^{25}$ Íbidem, p. 178.
} 
Además, la escasez de estas figuras no sugiere la representación de exvotos o representaciones personalizadas de individuos como se indicarían para otras figurillas del Mediterráneo Oriental. El predominio de las figuras masculinas sobre las femeninas ha sido relacionado con la hipótesis del papel dominante masculino en las sociedades de la Prehistoria Reciente, como signo del uso de la fuerza y la actividad bélica relacionada con el aumento de fortificaciones y armas. La representación masculina en la iconografía del III milenio a.n.e. sobre la tradicional femenina, nos revelaría una nueva realidad social y la necesidad de que el poder político tenga su referente en las manifestaciones ideológicas.

En Valencina podemos encontrarnos con tres ídolos de estas características. Los dos primeros fueron hallados en el Pozo número 1 del Sector Norte del Cerro de la Cabeza, uno de los cinco pozos que, de aspecto similar a silos, no poseen una interpretación aparente para los autores ${ }^{26}$. Estas estructuras fueron colmatadas en una fase precampaniforme del poblado y tenían alrededor de $1 \mathrm{~m}$ de diámetro con una profundidad que llegó a alcanzar en dos ocasiones $\operatorname{los} 10 \mathrm{~m}^{27}$. Ambos son ídolos antropomorfos masculinos de brazos cruzados que poseen una altura de 15,2 cm para el primero (fig. 3) y 11,5 cm el segundo (fig. 4). El primero de estos se halló a una profundidad de 7,91 m, mientras que el segundo apareció a 9,56 m.

Figura 3: Dibujo del ídolo antropomorfo en hueso.

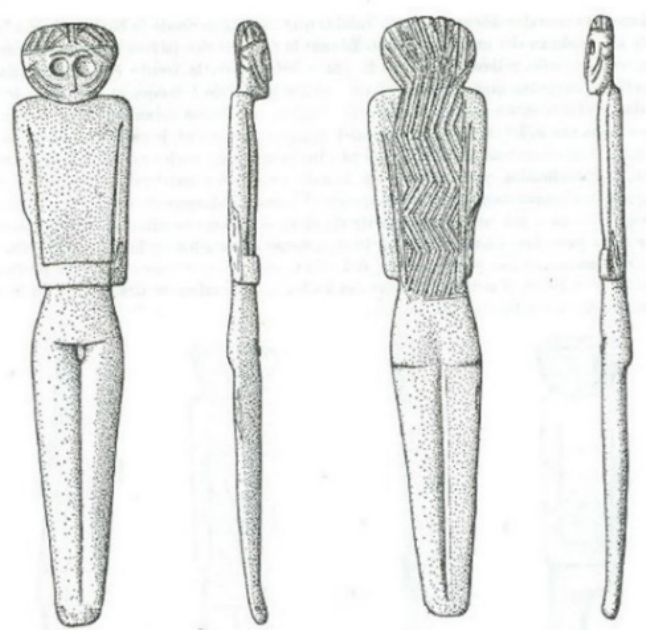

Fuente: Fernández Gómez, Fernando y Diego Oliva Alonso, “Ídolos calcolíticos del...” op. cit., p. 27.

\footnotetext{
${ }^{26}$ Fernández Gómez, Fernando y Diego Oliva Alonso, “Ídolos calcolíticos del...” op. cit.

${ }^{27}$ Íbidem, pp. 43-44.
} 
Figura 4: Dibujo del segundo ídolo antropomorfo en hueso.
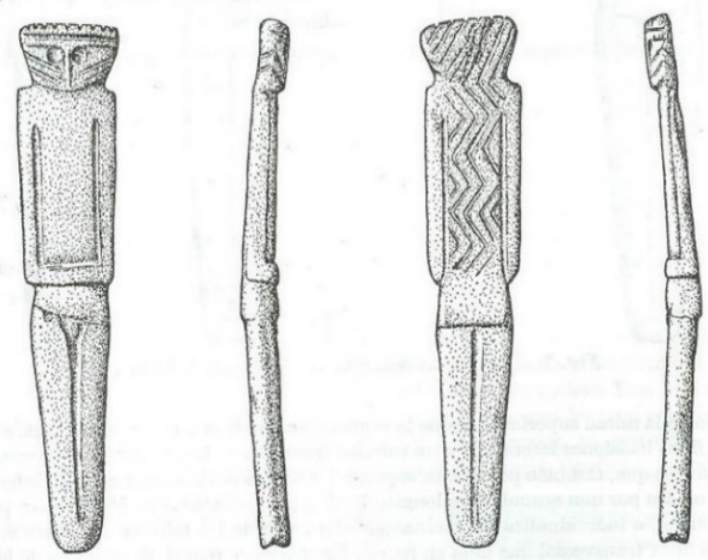

Fuente: Fernández Gómez, Fernando y Diego Oliva Alonso, “Ídolos calcolíticos del...”op. cit., p. 28.

El tercero fue hallado en la campaña de excavación del Plan Parcial de Matarrubilla en $2004^{28}$. De esta pieza realizada en marfil sólo se conoce la mitad inferior del ídolo masculino (fig. 5). Con una altura conservada de $4,8 \mathrm{~cm}$, únicamente podemos observar los glúteos que se indican por un rebaje horizontal, así como una separación entre las piernas por una acanaladura vertical. El hallazgo se produjo en el transcurso de la limpieza de la denominada Estructura 50.

Figura 5: Dibujo del ídolo antropomorfo en marfil.

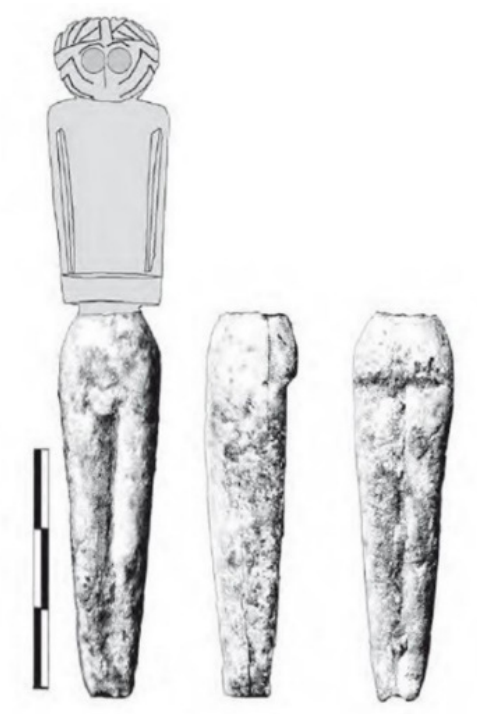

Fuente: Hurtado Pérez, Víctor, “Ídolos del asentamiento...” op. cit., p. 314.

\footnotetext{
${ }^{28}$ Nocete Calvo, Francisco et al., "The smelting quarter of Valencina de la Concepción (Seville, Spain): the specialised copper industry in a political centre of the Guadalquivir valley during the Third millennium BC (27502500 BC)", en Journal of Archaeological, Science, 35 (2008), pp. 717-732. DOI: http://dx.doi.org/10.1016/j. jas.2007.05.019; y Hurtado Pérez, Víctor, "Ídolos del asentamiento..." op. cit., pp. 313-314
} 


\section{2 Ídolos oculados sobre hueso}

Este tipo de ídolos se caracterizan por la representación de ojos, cejas, tatuaje facial y, a veces, líneas en zigzag en el reverso a modo de cabello. En general estos ídolos se realizan sobre soportes pétreos, pero existen otras variantes formales en las que se plasma esta representación ${ }^{29}$. Habituales del Sur peninsular, se ha pensado que puedan poseer un significado común, pero que se representa o interpreta estilísticamente de distintas formas de acuerdo a diferentes regiones geográficas, lo que también se podría relacionar con una intencionalidad de marcar una identidad territorial como así lo apuntan varios autores ${ }^{30}$. Como por ejemplo, el número de hallazgos de ídolos oculados sobre piedra son más comunes en la zona del Suroeste peninsular, mientras que en el extremo opuesto son habituales los realizados sobre hueso, lo que no implica la no presencia de los distintos tipos en diferentes regiones.

A la hora de interpretar estos ídolos peninsulares se han esgrimido muchas hipótesis ${ }^{31}$ : protectores de difuntos, elementos de ceremonias funerarias, marcadores sociales, recuerdo de antepasados o de linajes, representaciones de personajes bajo la influencia de drogas... son muchos los problemas con los que nos encontramos cuando queremos darles un significado concreto. La falta de contextos precisos, ya que un gran número de ellos proceden de excavaciones antiguas, complican esta tarea aún más. Gimbutas ${ }^{32}$ defendió la existencia de una diosa paneuropea pero, aunque hemos visto que existe una idea común peninsular expresada en los ojos y materializada en distintas representaciones, no podemos asegurar la existencia mayoritaria de figurillas femeninas en contra de figuras masculinas, aunque sean elementos frecuentes en las sociedades de los primeros campesinos en diversos lugares del planeta.

Es por ello que aún no podemos responder a la pregunta sobre qué representan realmente estos ídolos. Teniendo en cuenta que muchas piezas no pueden considerarse directamente ídolos por estar realizadas sobre un determinado soporte, los expresivos ojos tendrían distintas interpretaciones a través de los diferentes soportes sobre los que se manifiestan. Para Maicas ${ }^{33}$, cada pieza tendrá un valor individual por sí misma y lo hace mediante un complejo sistema de elaboración que no repite esquemas decorativos, pero puede perder su valor simbólico inicial y ser reciclado. La llegada de la Edad del Bronce y la caída del motivo oculado, se corresponde con el predominio del antropomorfo masculino que parece estar asociado a los nuevos esquemas sociales y de culto.

Entrando ya en aspectos más formales, dentro de este tipo de ídolos podemos hacer una subdivisión de conjuntos sobre soporte orgánico, como son los ídolos placa, ídolos sobre

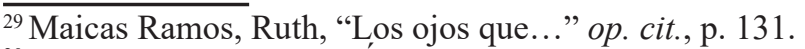

${ }^{30}$ Hurtado Pérez, Víctor, "Ídolos, estilos y..." op. cit., p. 5; Pajuelo Pando, Ana y Pedro López Aldana, "Ideología de un centro de poder. Nuevos productos ideológicos de Valencina (Sevilla)", en Actas del VI Encuentro... op. cit., pp. 501-520.

${ }^{31}$ Maicas Ramos, Ruth, "Los ojos que..." op. cit., p. 130.

${ }^{32}$ Gimbutas, Marija, El lenguaje de la diosa, Oviedo, Editorial Dove, 1996.

${ }^{33}$ Maicas Ramos, Ruth, "Los ojos que..." op. cit., p. 132-133.
} 
huesos largos, ídolos espátulas o ídolos sobre asta decorada que no han sido añadidos en este trabajo ya que no aparecen en el contexto arqueológico de Valencina. En primer lugar debemos hacer mención al conjunto de ídolos falange (fig. 6). Estas manifestaciones, documentadas desde contextos paleolíticos y en puntos muy distantes de la geografía, han sido clasificadas según la modificación que ha sufrido el soporte, distinguiendo entre piezas decoradas, piezas modificadas y piezas sin transición intencional ${ }^{34}$. Su interpretación hasta el momento nos es desconocida, aunque algunos autores ${ }^{35}$, como hemos citado, los ha querido relacionar con una diosa paneuropea, debido a la representación del triángulo sexual femenino en muchas de ellas. La mayor parte de las piezas recuperadas de Valencina han sido documentadas por Fernández Gómez y Oliva Alonso $^{36}$, y Hurtado ${ }^{37}$ estando las cinco primeras aquí descritas gracias a sus estudios:

—Ídolo "falange" de bóvido (fig. 6A). Ídolo realizado sobre una diáfisis distal de metatarso de Bos taurus, de la cual solo se conserva la parte inferior en la que, a un lado y otro de su acanaladura vertical natural, aparecen cinco profundas incisiones horizontales paralelas que se pierden en la parte posterior, sin llegar a unirse en su trazado - con distancias variables entre 5 y $13 \mathrm{~mm}$ - Está fragmentado de antiguo, siguiendo la línea de dos incisiones horizontales, por lo que su altura máxima es $7,5 \mathrm{~cm}$. Se halló en el Pozo número 31 del Sector del Cerro de la Cabeza a 7,75 $\mathrm{m}$ de profundidad.

- Ídolo falange de bóvido (fig. 6B). Realizado sobre una primera falange de Bos taurus a la que se han eliminado todas las protuberancias dejando la pieza alisada. Presenta un buen estado de conservación, aunque sí posee algunas señales de desgaste. Con una altura de 5,5 cm apareció en el Pozo número 1 del Sector del Cerro de la Cabeza a 6,21 $\mathrm{m}$ de profundidad.

- Ídolo falange de suido (fig. 6C). Realizado sobre una primera falange de suido carece también de decoración. El artista o artesano únicamente se limitó a intentar eliminar las protuberancias del hueso frotándolo directamente contra una superficie abrasiva, que ha provocado marcados planos lisos continuos con aristas bien definidas. En buen estado de conservación, posee 3,5 cm de altura. Fue hallado en el Pozo número $31 \mathrm{del}$ Sector del Cerro de la Cabeza a 8,10 m de profundidad en la base del pozo.

- Ídolo falange de équido (fig. 6D). Realizado sobre una primera falange de Equus $s p$., carece de decoración, ya que únicamente se han limitado a limar todas las protuberancias superficiales del hueso dejándolo alisado. Asimismo, se han eliminado también por abrasión, una de las protuberancias centrales de la porción proximal del hueso que aparece biselada. Con una altura total de $7,1 \mathrm{~cm}$, fue hallado en la limpieza superficial de la Cabaña F70.

\footnotetext{
${ }^{34}$ Íbidem, p. 120.

${ }^{35}$ Gimbutas, Marija, El lenguaje de... op. cit.

${ }^{36}$ Fernández Gómez, Fernando y Diego Oliva Alonso, "Ídolos calcolíticos del...” op. cit., pp. 34-35.

${ }^{37}$ Hurtado Pérez, Víctor, "Ídolos del asentamiento..." op. cit., p. 320.
} 
- Ídolo falange de ciervo (fig. 6E). Realizado sobre una primera falange de cérvido, únicamente se presenta alisado. En la cara dorsal, el excesivo desgaste del hueso ha provocado una pequeña fractura. Aunque en la porción distal también se han alisado las protuberancias laterales del hueso, se distinguen netamente las oquedades centrales a modo de ojos. A excepción de la pequeña fractura, el ídolo posee una buena conservación y un intenso pulimento. Con una altura de 4,5 cm apareció en el Pozo número 31 del Sector del Cerro de la Cabeza a $6,30 \mathrm{~m}$ de profundidad.

Figura 6: Dibujo del conjunto de ídolos falange hallados hasta 1980.

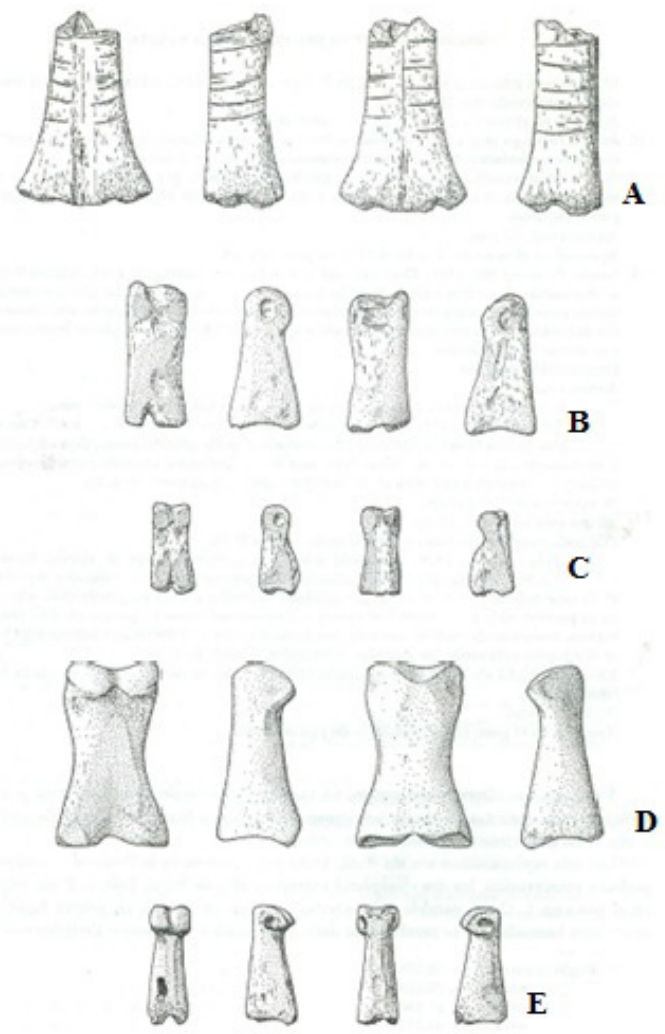

Fuente: Fernández Gómez, Fernando y Oliva Alonso, Diego, "Ídolos calcolíticos del...” op. cit., p. 36.

Otro de ellos, y entrando en la categoría de "falanges decoradas" (fig. 7), fue el hallado en el Sector Avenida de Andalucía por Sardá Piñero ${ }^{38}$. Este ídolo aparece decorado por ambas caras con una técnica mixta de grabado y pirograbado: se considera que primero grabarían los motivos con líneas incisas y después se aplicaría sobre ellas un objeto ardiente. Además, posee decoración pintada en tono rojizo. La cara plantar aparece muy deteriorada en la mitad inferior, con parte de la superficie rebajada; aunque podría apreciarse la existencia de dos

\footnotetext{
${ }^{38}$ Sardá Piñero, Diego, "Estructuras negativas multifuncionales en Avenida de Andalucía no 9, Valencina de la Concepción (Sevilla)", en García Sanjuán, Leonardo et al. (eds.), El asentamiento prehistórico... op. cit., pp. 151156.
} 
círculos radiados hacia el exterior a modo de ojos, una línea vertical entre ellos y dos pares de líneas quebradas en ángulo recto a modo de L invertidas y opuestas entre sí. Por otro lado, en el reverso se dibujan doce líneas onduladas en horizontal que ocupan más de la mitad superior y, bajo ellas, dos líneas horizontales rectas con pequeños trazos perpendiculares cruzándolas. Apareció en la Estructura CUE 45, correspondiéndose posiblemente con un silo o pozo del que no se aporta más información.

Figura 7: Dibujo del ídolo falange decorado.

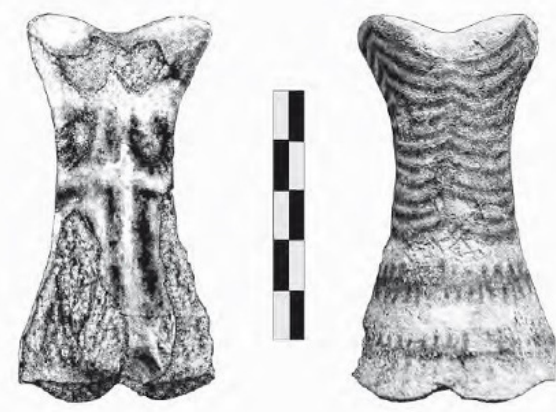

Fuente: Hurtado Pérez, Víctor, “Ídolos del asentamiento...” op. cit., p. 320.

Como señala Hurtado ${ }^{39}$, se tiene noticia de otros posibles ídolos falanges hallados durante las excavaciones de urgencia en la finca La Candelera de las que no se tienen muchos más datos. Murillo hace un breve informe de la intervención donde no se especifican ni sus características ni las circunstancias del hallazgo de estos materiales, quedando constancia de un dibujo de lo que parecen ser dos ídolos falange, uno de ellos con incisiones en la parte superior ${ }^{40}$.

Dentro de este mismo grupo de ídolos oculados nos encontramos con este pequeño ídolo cilindro oculado en hueso (fig. 8). Según nos recogen Martín Espinosa y Ruiz Moreno ${ }^{41}$ en un hallazgo de las excavaciones de urgencia en la finca La Gallega. Esta pieza sólo conserva su mitad superior con una altura máxima de $4,1 \mathrm{~cm}$ y $0,9 \mathrm{~cm}$ de diámetro de sección circular. Estaría realizado sobre un hueso largo y no posee una forma exacta de cilindro, ya que presenta una pequeña disminución del diámetro a la altura de los ojos.

\footnotetext{
${ }^{39}$ Hurtado Pérez, Víctor, "Ídolos del asentamiento..." op. cit., p. 320.

${ }^{40}$ Murillo Díaz, Teresa, "Excavaciones de urgencia en el poblado calcolítico de Valencina de la Concepción (Sevilla) 1988-1989”, en Anuario Arqueológico de Andalucía 1989, Sevilla, Junta de Andalucía, 1989, pp. 555-560.

${ }^{41}$ Martín Espinosa, Amparo y María Teresa Ruiz Moreno, "Dos ídolos calcolíticos en «La Gallega», Valencina de la Concepción, Sevilla”, en Madrider Mitteilungen, 37 (1996), pp. 7-8.
} 
Figura 8: Dibujo de ídolo cilindro en hueso.
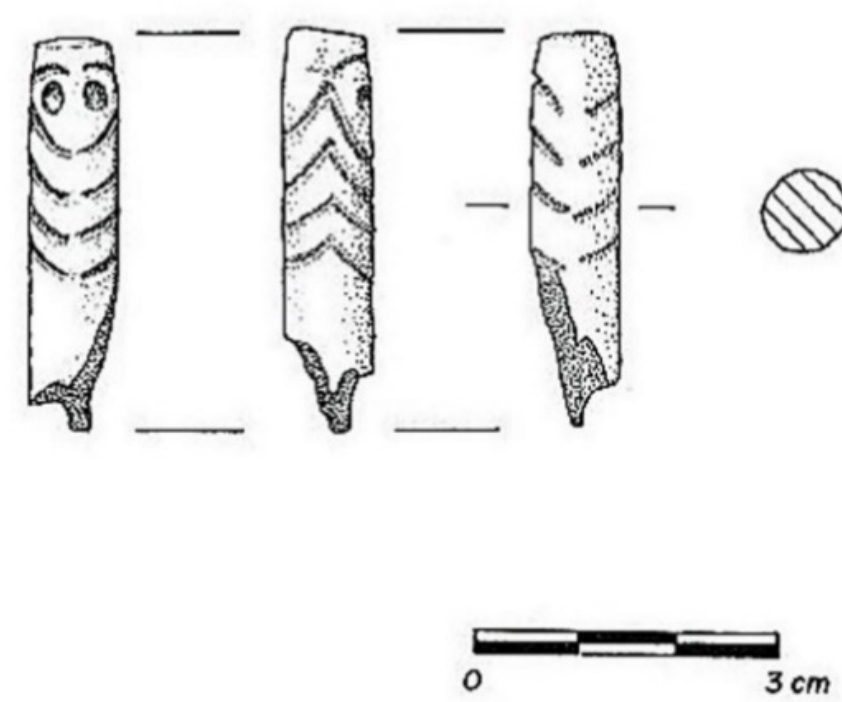

Fuente: Martín Espinosa, Amparo y María Teresa Ruiz Moreno, “Dos ídolos calcolíticos...” op. cit., p.7.

La decoración está realizada mediante incisión de sección en $\mathrm{V}$ profunda y ancha, siendo la parte más destacada las oquedades oculares, sobre las que se representan dos líneas arqueadas a modo de cejas. Bajo los ojos no falta el tatuaje facial, cuatro líneas paralelas que se inician de forma concéntrica a los ojos, dibujando después un ángulo acusado en los laterales, para terminar en la cara posterior del mismo modo que en la delantera. Quedando estas líneas sin unirse, comienzan en su cara frontal con trazos a la misma altura, dos a dos, mientras que en la parte posterior casi se cruzan, dejando un espacio intermedio irregular. En cuanto a su conservación parece haber sufrido los efectos de los roedores, de acuerdo a las huellas que se observan en su superficie.

\section{Otros objetos suntuosos de Valencina}

Además de estas espectaculares representaciones simbólicas sobre hueso y el ídolo sobre marfil, existen otros objetos, elaborados especialmente en esta última materia, que hacen todavía más singular a este yacimiento del Suroeste peninsular. Su posible especialización artesanal - por haberse hallado una zona de trabajo en el poblado ${ }^{42}$ - así como su estética y gusto a la

\footnotetext{
${ }^{42}$ Nocete Calvo, Francisco et al., "The ivory workshop of Valencina de la Concepción (Seville, Spain) and the identification of ivory from Asian elephant on the Iberian Peninsula in the first half of the 3rd millennium BC", en Journal of Archaeological Sciencie, 40 (2013), pp. 1579-1592. DOI: https://doi.org/10.1016/j.jas.2012.10.028; Vargas Jiménez, José Manuel et al., "Contextos de producción de objetos de marfil en Valencina de la Concepción
} 
hora de realizarlos, se combina con ser la única área peninsular de contacto de marfil asiático y africano en un mismo período de tiempo ${ }^{43}$. Para hacer más cómoda su lectura, se ha decidido enumerar los principales objetos de marfil según su lugar de aparición y no por tipología como realizamos en el apartado anterior. La mayoría de estos objetos han sido hallados en contextos funerarios formando o no partes del ajuar de los individuos depositados.

Comenzando por los hallazgos más antiguos, en 1919, dentro del dolmen de Matarrubilla se encontró una cámara supuestamente expoliada, donde únicamente se pudieron recuperar varios restos cerámicos y un posible brazalete de marfil, según lo recoge la descripción realizada por Obermaier y su dibujo adjunto ${ }^{44}$. En la actualidad esta pieza se encuentra perdida pero, según las informaciones que nos quedan, algunos especialistas como Schuhmacher han valorado este "brazalete" como una porción de marfil en bruto ${ }^{45}$. Siguiendo la línea cronológica, el segundo hallazgo se llevó a cabo durante las intervenciones de 1948 en el dolmen de Ontiveros. Este objeto parece ser un peine fragmentado realizado en marfil, que también hoy se encuentra perdido, quedándonos una descripción y un dibujo realizado por Carriazo y Arroquia en 196146. Continuando con el estudio del dolmen de Matarrubilla por Collantes Terán en 1969, se pudo recuperar el primer conjunto de elementos realizados en marfil - ya que fueron catalogados como parte del ajuar del monumento-, con más de 100 objetos todavía conservados en el Museo Arqueológico de Sevilla (fig. 9) ${ }^{47}$.

Además de todos estos, el conjunto más destacable es el de cuarenta cuentas tubulares múltiples. Estas piezas presentan una decoración en la parte del anverso, con varios tubos perforados unidos por su lado longitudinal mientras que su reverso es plano y presentan unas complicadas perforaciones laterales. Su forma, así como el número de tubos huecos, sería variable, lo que podría indicar una posible ordenación. Así, Schuhmacher y otros autores ${ }^{48}$ han propuesto una hipotética reconstrucción de un pectoral formado por estas cuentas estableciendo un orden de las cuentas más estrechas en los extremos pasando por las más anchas en el centro-, del que habría que tener en cuenta que no hay paralelos hasta el momento conocidos (fig. 10).

(Sevilla)", en Banerjee, Arun et al. (eds.), Actas del coloquio internacional "Marfil y elefantes en la Península Ibérica y el Mediterráneo Occidental”, Londres, Deutsches Archäologisches Institut Alicante, Diputación de Alicante, 2012, pp. 69-81.

${ }^{43}$ García Sanjuán, Leonardo et al., "Ivory craftsmanship, trade and social significance in the southern Iberian Copper Age: the evidence from the PP4-Montelirio sector of Valencina de la Concepción (Sevilla, Spain)", en European Journal of Archaeology, vol. 16, 4 (2013), p. 621. DOI: https://doi.org/10.1179/1461957113Y.0000000037.

${ }^{44}$ Obermaier, Hugo, El domen de Matarrubilla, Madrid, Museo Nacional de Ciencias Naturales, 1919.

${ }^{45}$ Schuhmacher, Thomas Xaver et al., "Los marfiles del yacimiento de Valencina de la Concepción (Sevilla) en el contexto del Calcolítico del suroeste peninsular”, en García Sanjuán, Leonardo et al. (eds.), El asentamiento prehistórico... op. cit., p. 497.

${ }^{46}$ De Mata Carriazo y Arroquia, Juan, "El dolmen de Ontiveros (Valencina de la Concepción), en VV. AA., Homenaje al Profesor Cayetano de Mergelina, Murcia, Universidad de Murcia, 1962, pp. 209-229.

${ }^{47}$ Schuhmacher, Thomas Xaver et al., "Los marfiles del..." op. cit., p. 497.

${ }^{48}$ Ibídem, p. 498. 
31 Cristina Cabrera Taravillo, "Algunos hallazgos votivos y suntuarios en hueso y marfil..."

Figura 9: Dibujos de una selección de las piezas halladas en el corredor del dolmen de Matarrubilla.

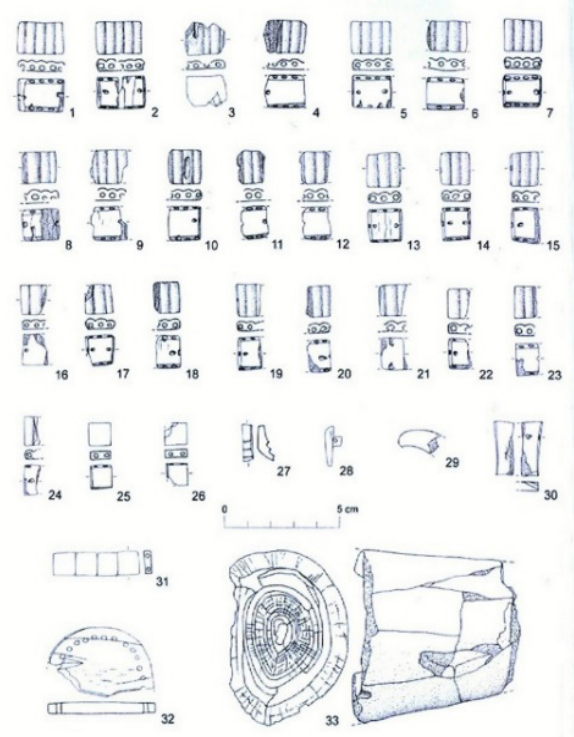

Fuente: Schuhmacher, Thomas Xaver et. al., "Los marfiles del..." op. cit., p. 497.

Figura 10: Dibujo del hipotético pectoral realizado a partir de las cuentas tubulares en marfil del dolmen de Matarrubilla.

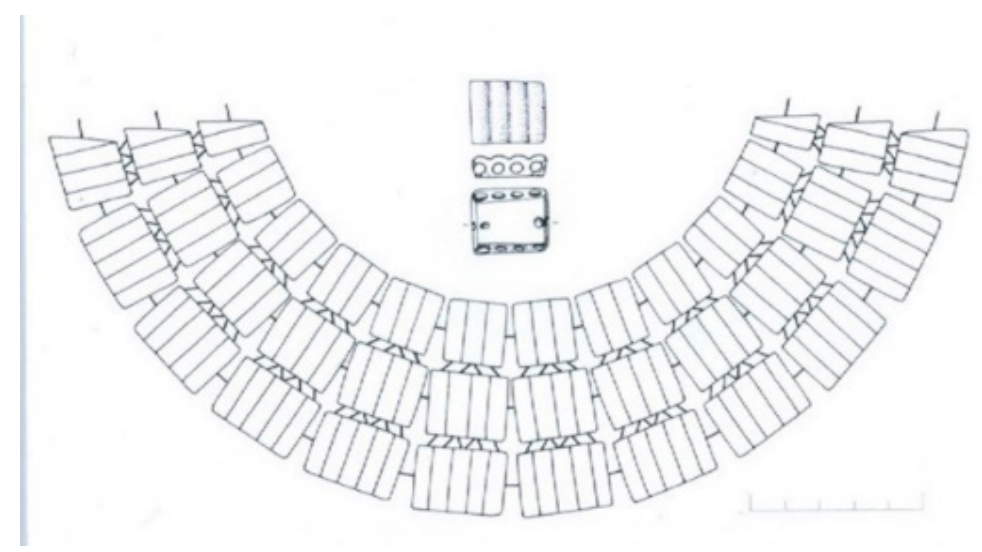

Fuente: Schuhmacher, Thomas Xaver et al., "Los marfiles del...” op. cit., p. 498.

Las siguientes dos sepulturas, intervenidas durante las campañas de 2007 y 2008 dentro del Sector PP4-Montelirio, se siguen estudiando en la actualidad por lo que muchos de sus materiales están inéditos. La primera de ellas se trata de una estructura en forma de tholos denominada Montelirio, donde se han podido documentar algunas piezas excepcionales en marfil como un vaso, una paleta-espátula, algunas figuritas zoomorfas y varios objetos en 
forma de bellota ${ }^{49}$ (fig. 11). Estos materiales no serían únicos dentro de este registro, ya que guardan amplias similitudes con los hallados en el yacimiento portugués de Perdigões ${ }^{50}$ y otros del Suroeste peninsular. Este tipo de representaciones zoomorfas han sido muy difícilmente interpretables, ya que estos pequeños objetos portables parecen carecer de una utilidad práctica. Pero sin lugar a dudas, este tipo de piezas demuestran la relación mística y práctica de estas sociedades calcolíticas con el mundo natural que les rodea. El medio ambiente que les provee de recursos económicos también lo hace de imágenes y simbolismos que ayudan a los humanos en el acto de construir una identidad para sus grupos, así como para sí mismos ${ }^{51}$.

Figura 11: Bellotas y animales realizados en marfil hallados en el dolmen de Montelirio.

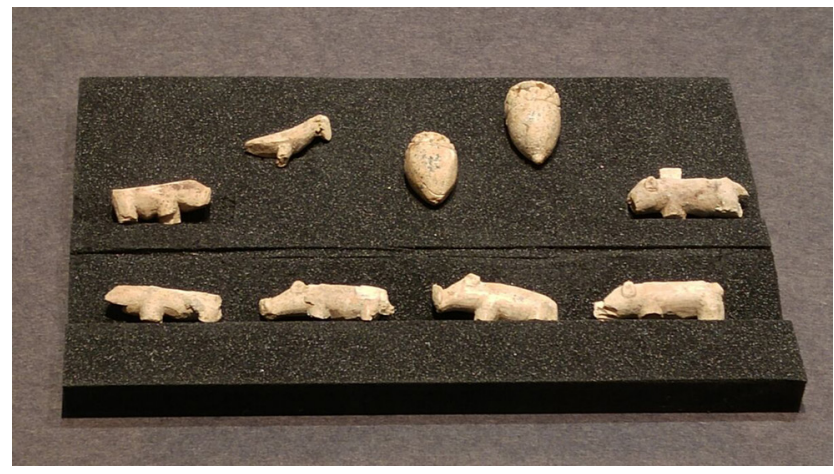

Fuente: fotografía realizada por la autora.

Además de estas figurillas de bulto redondo, en este mismo contexto se hallaron dos peines y una figura de ave que podría corresponder al extremo de una aguja. La única publicación acerca de estas piezas es la que hace referencia al par de peines, donde se indica la procedencia africana del material (fig. 12). Pudiendo observar su decoración, se ve representado lo que parece un grupo de seis antropomorfos inclinados, rodeados por otras representaciones zoomorfas que son interpretadas como suidos -que aparentemente podrían ser el mismo número que las humanas- en su parte superior, mientras que la inferior estaría compuesta por numerosas púas que le otorgarían la categoría intrínseca de peine o peineta ${ }^{52}$.

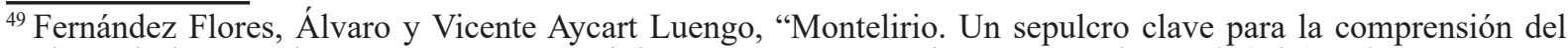
registro de los grandes monumentos megalíticos", en García Sanjuán, Leonardo et al. (eds.), El asentamiento prehistórico... op. cit., pp. 247-253.

${ }^{50}$ Valera, António, "The diversity of Ideotechnic objects at Perdigões Enclousure: a firts inventory of ítems and problems", en Arpi, 3 extra (2015), pp. 238-256.

${ }^{51}$ Valera, António et al., "Zoomorphic figurines and the problema of human-animal relationship in the Neolithic and Chalcolithic Southwest Iberia", en Menga: Revista de prehistoria de Andalucía, 5 (2014), pp. 15-41.

${ }^{52}$ Íbidem, pp. 25-26.
} 
Figura 12: Peinetas halladas en el Sector PP4-Montelirio.
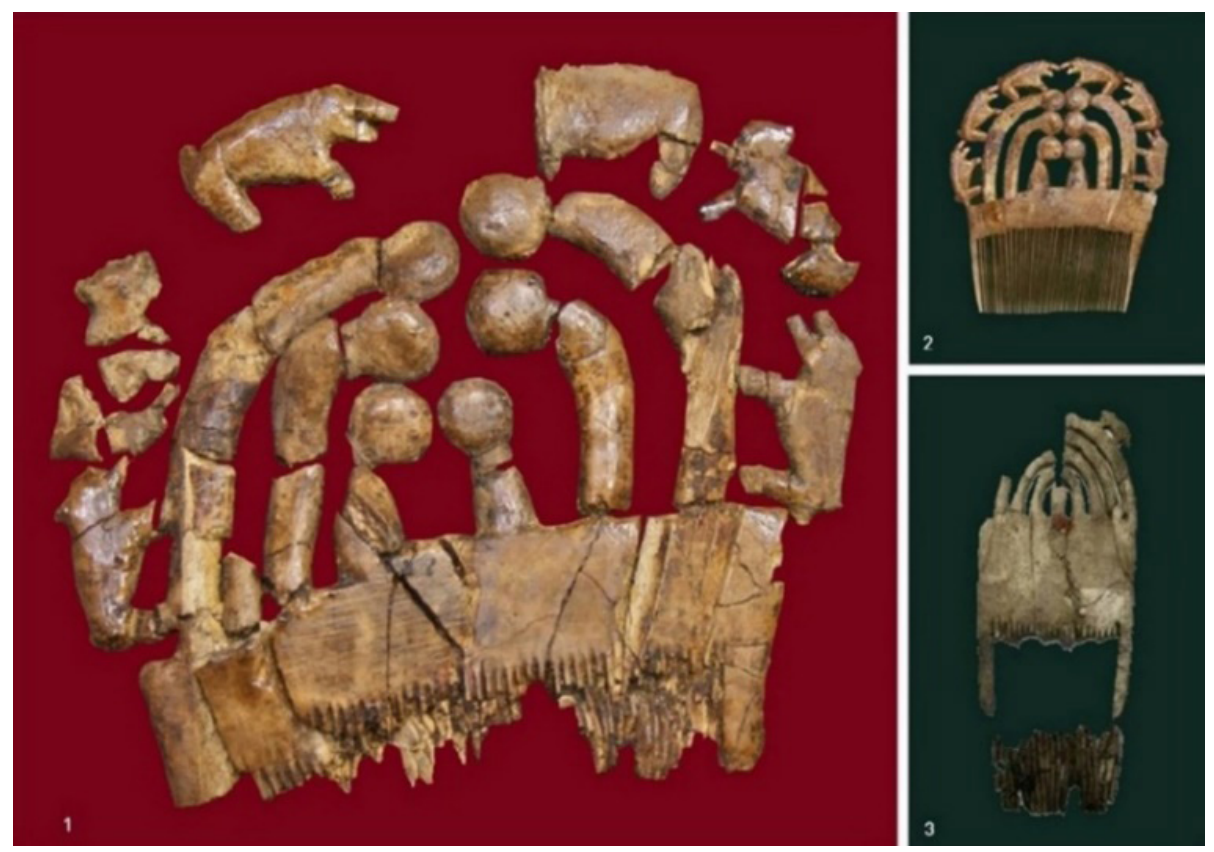

Fuente: Valera, António et. al., "Zoomorphic figurines and...” op. cit., figura 5. Notas: 1: estado actual de la peineta en marfil africano con representación zoomorfa; 2: reconstrucción hipotética; 3: restos del segundo peine de marfil.

Para finalizar con esta recopilación de materiales tenemos que citar una de las últimas estructuras funerarias estudiadas en Valencina, la denominada 10.042-10.049 del mismo Sector PP4-Montelirio. Esta estructura está compuesta por dos cámaras megalíticas con corredor. La primera de ellas está parcialmente destruida por las intervenciones urbanísticas realizadas en 1998 y posee un corredor con una longitud máxima de $12 \mathrm{~m}$ y recubierto por losas de pizarra. En ella se documentaron los restos de cuatro individuos, así como más de cincuenta objetos entre los que se encontraban miles de cuentas perforadas cubiertas por pigmento rojo, fragmentos cerámicos y líticos, así como otros objetos en hueso y marfil ${ }^{53}$.

En la segunda cámara, mejor conservada y también revestida de pizarra, se documentó un enterramiento individual con más de un centenar de objetos repartidos en dos niveles estratigráficos superpuestos, separados por un nivel deposicional de pizarras horizontales (figs. 13 y 14). En el inferior se halló una inhumación primaria de un individuo joven, masculino, decúbito lateral derecho, en dirección este-oeste y el cráneo orientado hacia el corredor. Acompañado de más de 30 piezas de ajuar —entre las que se encontraban varios platos cerámicos de borde almendrado, láminas de sílex, un pomo de ámbar siciliano o algunos objetos en cobre-, podemos destacar dos de ellas.

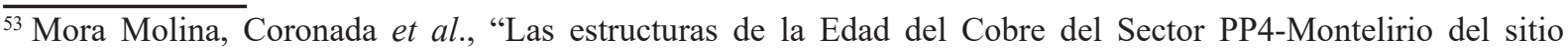
arqueológico de Valencina de la Concepción-Castilleja de Guzmán (Sevilla)", en García Sanjuán, Leonardo et al. (eds.), El asentamiento prehistórico... op. cit., pp. 261-280.
} 
Figura 13: Nivel 664 de la estructura 10.042-10.049 del Sector PP4-Montelirio.

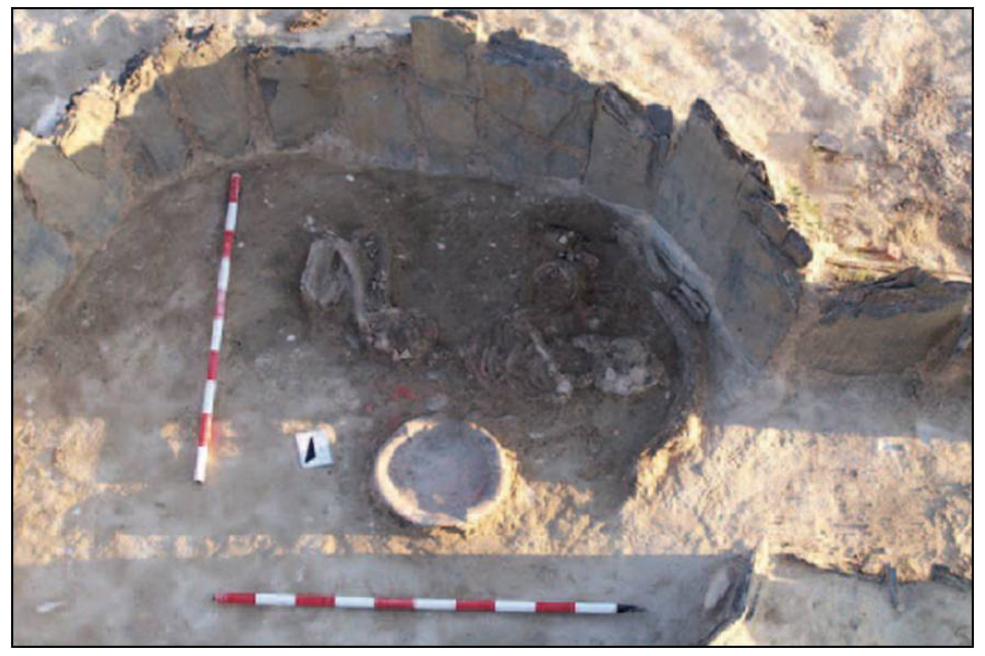

Fuente: Mora Molina, Coronada et al., "Las estructuras de..." op. cit., p. 268.

Figura 14: Nivel 535 de la estructura 10.042-10.049 del Sector PP4-Montelirio.

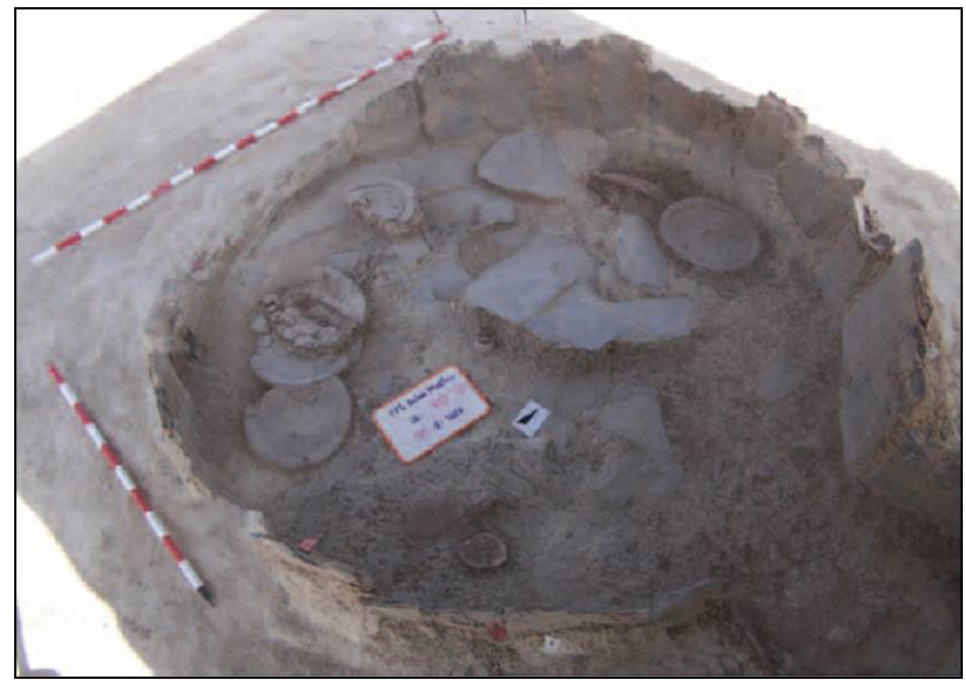

Fuente: Mora Molina, Coronada et al., "Las estructuras de..." op. cit., p. 268.

La primera sería un colmillo de elefante africano en bruto (fig. 15), rodeando la cabeza del individuo a modo de aureola. Con un peso de 1170,5 kg y una longitud de unos 59-60 cm de largo estaría sin decorar, únicamente fracturado en tres partes similares en tamaño y peso. Hasta 
el momento no se ha encontrado ningún paralelo de un hallazgo similar para el Calcolítico peninsular ${ }^{54}$.

Figura 15: Estado actual del colmillo de elefante africano hallado en la estructura 10.04210.049 en el Sector PP4-Montelirio.

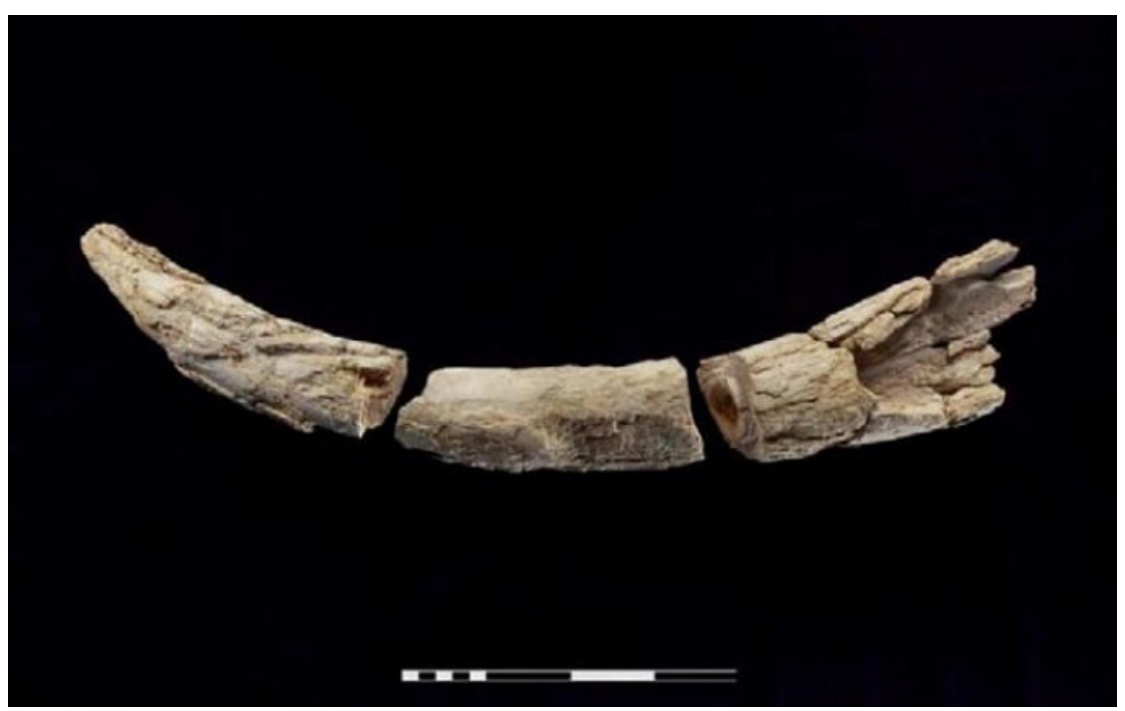

Fuente: García Sanjuán, Leonardo et al., "Ivory craftsmanship..." op. cit., figura 5.

El otro objeto suntuoso sería un vaso tallado en marfil asiático (fig. 16). Se trata de un recipiente cilíndrico de $6 \mathrm{~cm}$ de altura por $7,05 \mathrm{~cm}$ de diámetro máximo, cuya pared se adelgaza gradualmente hacia el exterior de la base. Está decorado hacia el exterior con tres líneas paralelas horizontales en el borde y, el resto, con cuadros piramidales. Este vaso podría haber sido contenedor tanto de líquidos como de sólidos, habiéndose encontrado otros paralelos similares en el Alentejo portugués y Extremadura; siendo los hallados en Perdigões los únicos elaborados en las mismas condiciones que este: en marfil y en una sola pieza ${ }^{55}$.

\footnotetext{
${ }^{54}$ García Sanjuán, Leonardo et al., "Ivory craftsmanship..." op. cit., p. 614.

${ }^{55}$ Íbidem, pp. 614-615.
} 
Figura 16: Estado actual del vaso realizado en marfil asiático hallado en la estructura 10.04210.049 en el Sector PP4-Montelirio.

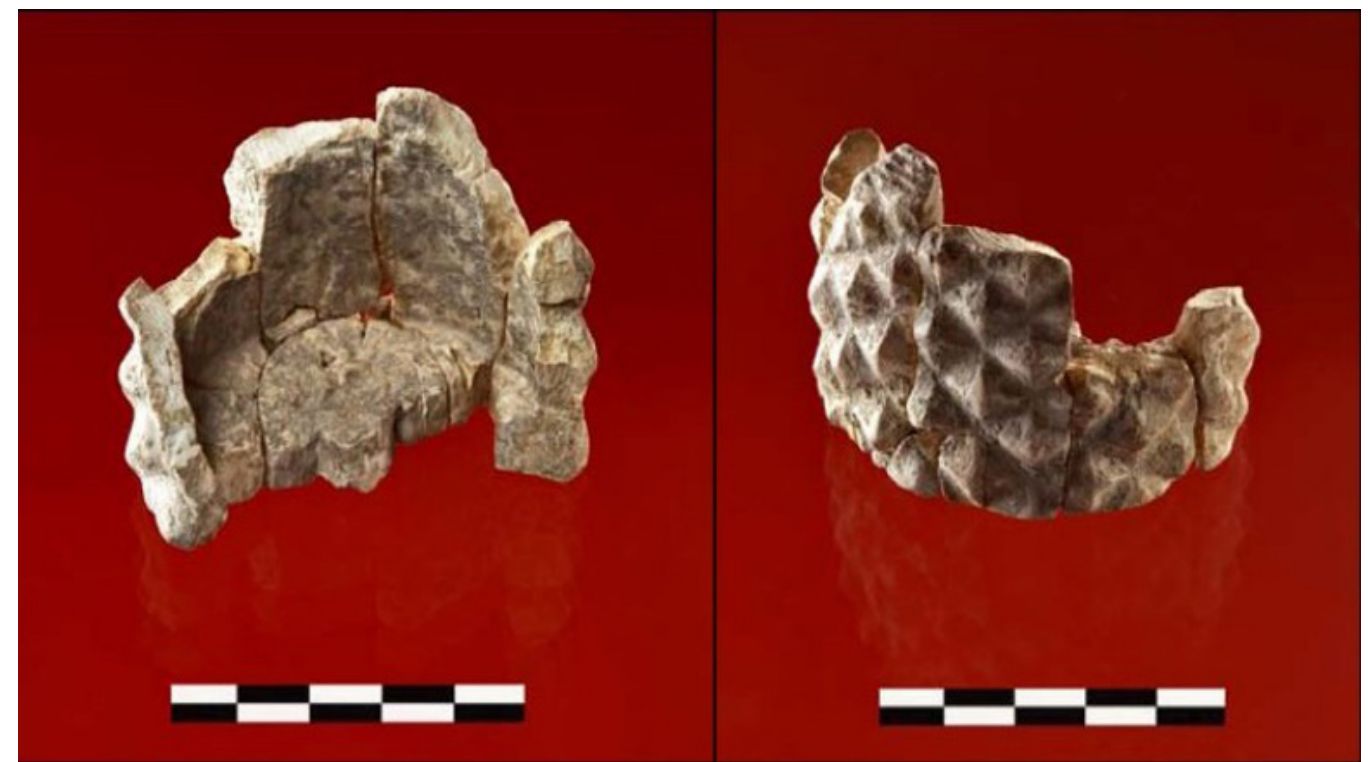

Fuente: García Sanjuán, Leonardo et al., "Ivory craftsmanship..." op. cit., figura 6.

En el segundo nivel estratigráfico de esta cámara no se encontraron restos óseos humanos, sino más de 70 piezas de diversa índole — cáscaras de huevo de avestruz, multitud de láminas y puntas de flecha en sílex, etc.-, entendido como un nivel deposicional de ajuar para el difunto del estrato inferior. Entre todos los ajuares tampoco faltan varios objetos en marfil de profusa decoración y valor simbólico. Destacar en un primer lugar una pieza proximal de colmillo de elefante asiático (fig. 17), esta se decoró en el exterior con varias bandas intercaladas de diversos motivos, como líneas incisas y formas piramidales en relieve. Su extremo final se completa con una protuberancia globular, que parece tener forma de bellota en donde, tras su estudio, se pudo observar una perforación de la que no se supo especificar si su realización fue intencionada, ya que se presenta muy fragmentada. Pese a esta deficiente conservación, la pieza posee una longitud de $30 \mathrm{~cm}$ de largo y un diámetro máximo de $4,25 \mathrm{~cm}$, pudiendo haber tenido unos 6 o $7 \mathrm{~cm}$ más de largo ${ }^{56}$. 
Figura 17: Estado actual del colmillo tallado en marfil asiático y detalle de los restos de cinabrio hallado en la estructura 10.042-10.049 en el Sector PP4-Montelirio.

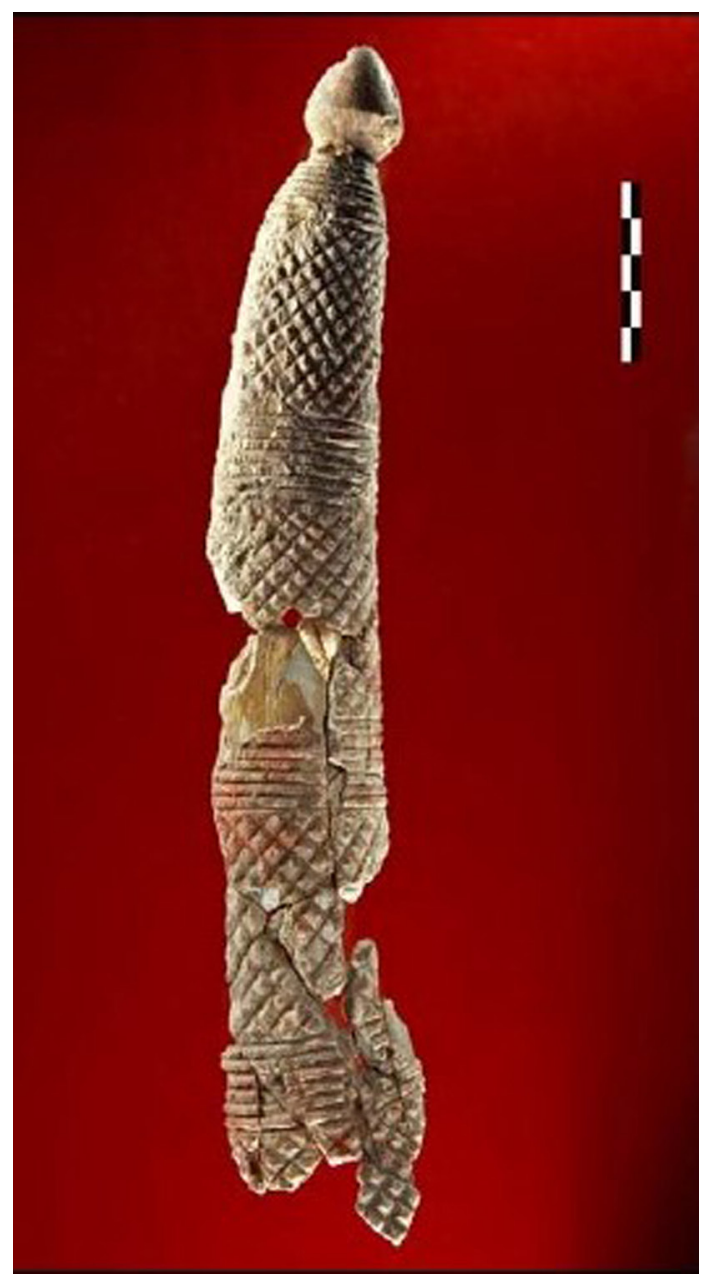

Fuente: García Sanjuán, Leonardo et al., "Ivory craftsmanship..." op. cit., figuras 8 y 9.

Próxima a ser interpretada como un "ídolo betilo", según la nomenclatura de Almagro Gorbea $^{57}$, esta defensa tan ricamente decorada no ha obtenido ninguna explicación, teniendo su paralelo más próximo en el yacimiento sevillano de La Molina, a unos $120 \mathrm{~km}$ al Este de Valencina ${ }^{58}$. Para estos investigadores se trataría de una clara representación fálica que se enmarcaría en este contexto, donde el simbolismo masculino parece predominar. Por otro lado, García Sanjuán y otros investigadores, priman por buscarle una funcionalidad a este objeto de Valencina ${ }^{59}$. La única relación que estos autores encuentran, debido a su forma, es con un recipiente para contener líquidos y/o sólidos. Además, si se prueba la resistencia de la perforación intencionada en su extremo, podría haber sido utilizado como un vaso para beber ${ }^{60}$.

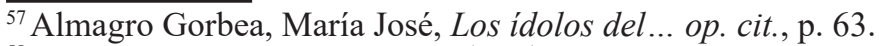

${ }^{58}$ Juárez Martín, José María et al., El enterramiento en cueva artificial de La Molina (Lora de Estepa, Sevilla), Sevilla, Consejería de Cultura de la Junta de Andalucía, 2010, p. 91.

${ }^{59}$ García Sanjuán, Leonardo et al., "Ivory craftsmanship..." op. cit., p. 616.

${ }^{60}$ Íbidem, p. 617.
} 
Las otras piezas que aquí destacamos serán el conjunto extraordinario de empuñadura y vaina realizadas sobre marfil asiático. La primera de ellas se halló al sur de la cámara, a la izquierda de la entrada y junto a una hoja tallada en cristal (fig. 18). Estaría compuesta por dos partes trabajadas por separado, que después fueron ensambladas una sobre otra:

- El pomo o remate superior posee entre 12 y $13 \mathrm{~cm}$ de largo, un diámetro de $1 \mathrm{~cm}$ y una anchura máxima de $4,5 \mathrm{~cm}$. Su decoración cuenta con ocho relieves en forma cónica que se han interpretado como el anverso de la pieza, mientras que su reverso contaría con 14 perforaciones alrededor del borde. Gracias a las fotografías de campo, se muestra que próximo a esta pieza se halló un conjunto de perlas perforadas, lo que hace pensar a los investigadores que estos huecos pudieron ser ocupados por ellas y que formaran parte de la pieza y su decoración.

- La empuñadura con unos 8,4 cm de largo, 4,5 $\mathrm{cm}$ de ancho y $1 \mathrm{~cm}$ de espesor, encaja perfectamente con el pomo gracias al ahuecamiento que posee en su base. Esta pieza estaría decorada en el centro de ambos lados con líneas en zigzags talladas en relieve que, en sus uniones, parecen formar pirámides. Sus bordes son decorados con una serie de tres o cuatro líneas paralelas, además de un hueco en su parte inferior para permitir la inserción de la hoja del puñal que terminaría por completar la pieza.

Figura 18: Estado actual de la empuñadura en marfil asiático hallada en la estructura 10.04210.049 en el Sector PP4-Montelirio.

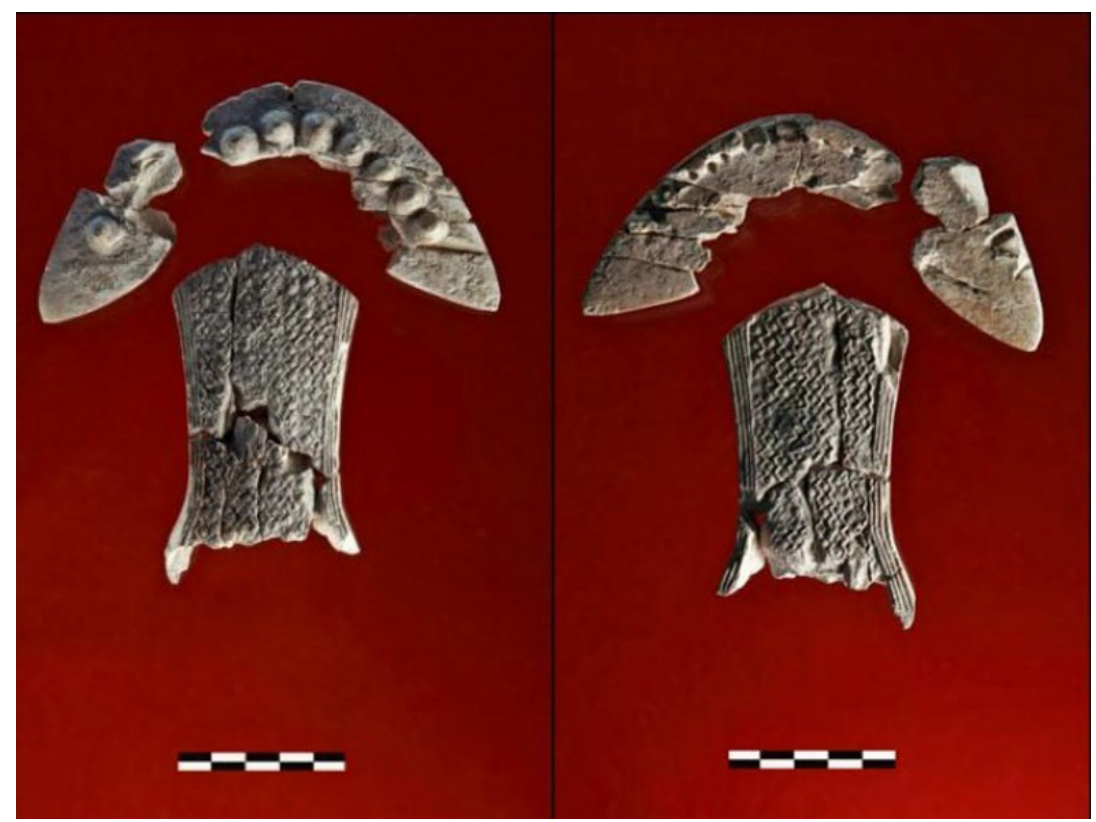

Fuente: García Sanjuán, Leonardo et al., "Ivory craftsmanship...”op. cit., figura 11. 
Existen algunas empuñaduras similares a las del yacimiento portugués de Perdigões, pero hasta el momento ningún paralelo posee una decoración tan rica como esta de Valencina ${ }^{61}$. La forma de media luna que resulta del conjunto de la empuñadura y el pomo sería un tanto excepcional, ya que son armas con un posible valor simbólico e indicativo de condición social, como así lo atestiguan las estelas decoradas del Alentejo portugués donde este útil es representado con bastante frecuencia ${ }^{62}$.

La otra parte de esta pieza la compondría la placa o vaina tallada también en marfil asiático (fig. 19). A pocos metros de la empuñadura y junto a la hoja de cristal de roca, se halló esta placa decorada de entre 0,4 y $0,6 \mathrm{~cm}$ de espesor y $25 \mathrm{~cm}$ de longitud en su estado actual de conservación. De extremo redondeado que se va estrechando a medida que se va acercando al centro, esta placa posee decoración en un único lado - lo que ha llevado a interpretar a los investigadores como su reverso-, con líneas en zigzags similares a la decoración de la empuñadura, pero a una escala mayor. Su reverso liso únicamente posee dos relieves que pudieron cumplir la función de apoyo para la empuñadura, ya que el arco del pomo y el extremo de la placa se encuentran en ese punto. En sus laterales se han podido observar al menos cuatro perforaciones en $\mathrm{V}^{63}$.

Figura 19: Estado actual de la placa interpretada como funda en marfil asiático para el puñal hallado en la estructura 10.042-10.049 en el Sector PP4-Montelirio.

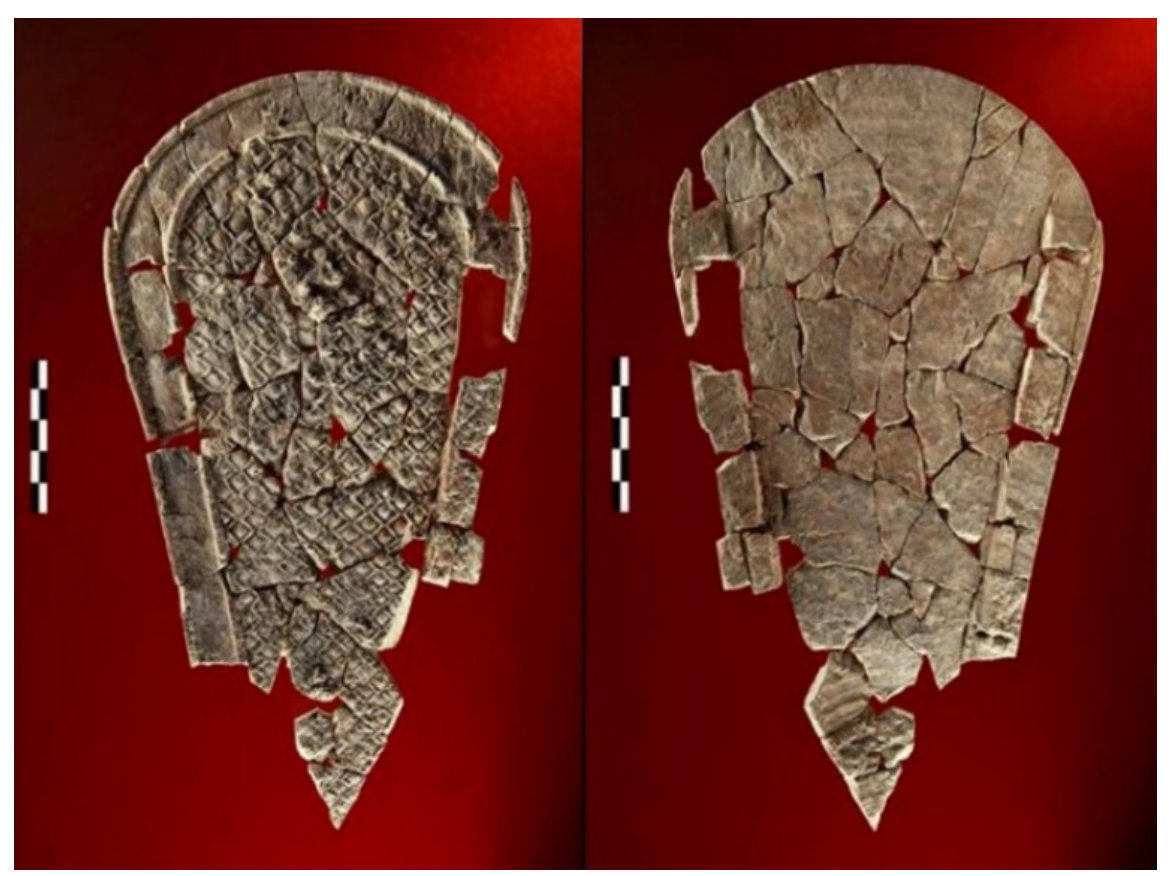

Fuente: García Sanjuán, Leonardo et al., "Ivory craftsmanship...”op. cit., figura 14.

\footnotetext{
$\overline{{ }^{61} \text { Íbidem, p. } 616 .}$

${ }^{62}$ Díaz-Guardamino Uribe, Marta, Las estelas decoradas en la Prehistoria de la Península Ibérica, Madrid, Servicio de Publicaciones de la Universidad Complutense, 2010, pp. 293-326.

${ }^{63}$ García Sanjuán, Leonardo, et al., "Ivory craftsmanship...” op. cit., pp. 627-628.
} 
Estas placas habían sido interpretadas en la bibliografía como objetos votivos o rituales —denominadas como "ídolos en forma de sandalia", "sandalias votivas" o "sandaliformes" por autores como Luis Siret o el matrimonio Leisner- debido al desconocimiento de su utilidad y al hábito de utilizar el cliché de "ritual" para todo aquello que no es conocido. Pero gracias a las condiciones de este hallazgo y la interpretación de sus investigadores ${ }^{64}$, se les ha podido otorgar la función de vaina, funda o estuche para puñales (fig. 20). Este útil hubiera constado de dos partes, la propia plaqueta en material duro y un paño o cuero que iría cosido a la placa por las perforaciones en V. Un objeto que hallado en otros yacimientos como Almizaraque, Alapraia o Los Millares carecía de interpretación y que ahora podemos otorgar una funcionalidad práctica, aunque muy vistosa y de compleja ejecución (fig. 21).

Figuras 20 (derecha) y 21 (izquierda): Reconstrucción del puñal y una hipótesis de cómo podría haberse portado dicho conjunto.
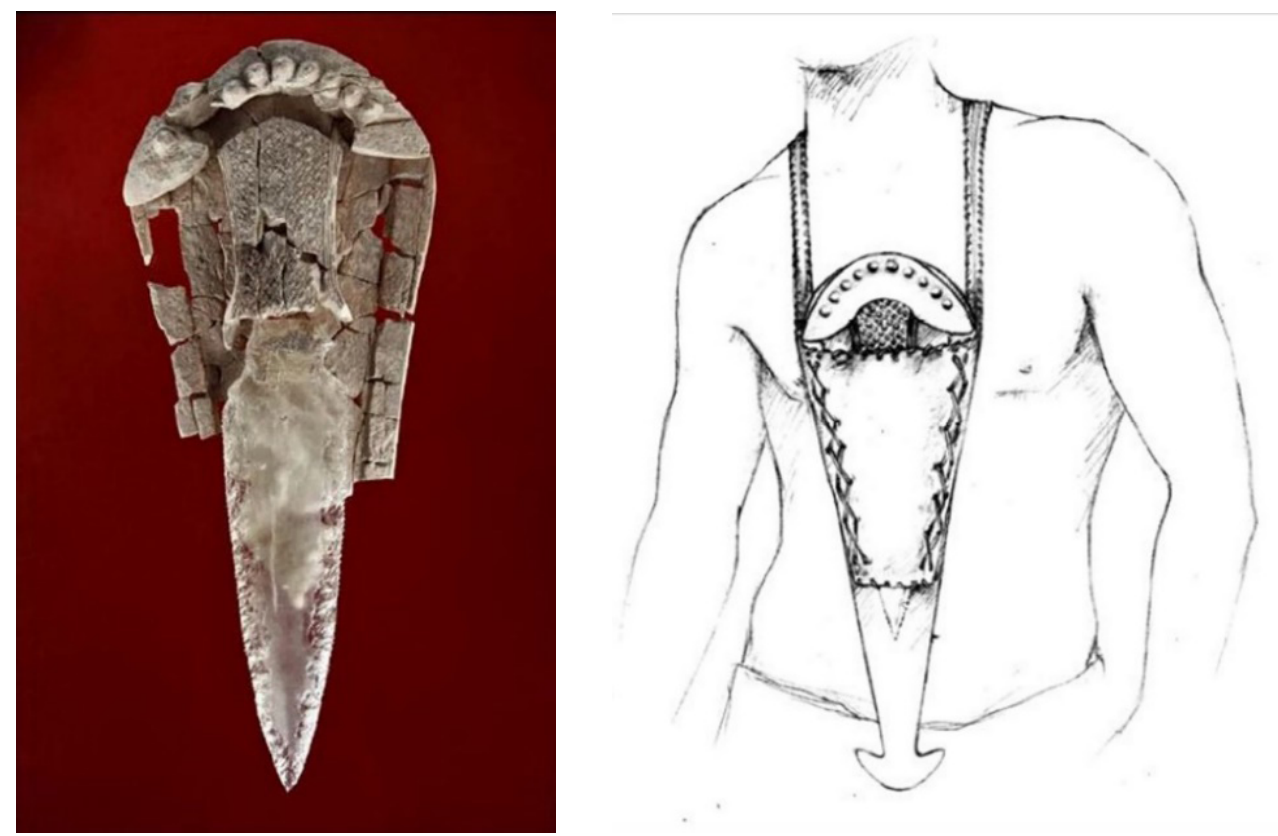

Fuente: García Sanjuán, Leonardo et al., "Ivory craftsmanship...” op. cit., figuras 16 y 17. 
4. Consideraciones finales: el mundo simbólico de Valencina

Valencina de la Concepción es un yacimiento complejo, debido tanto a su extensión como a su heterogeneidad espacial. La elección exclusiva de soportes óseos para la realización de este trabajo se debe, en primera instancia, a una elección personal. Ciertamente, seleccionar en función de la materia prima con la que se elaboran los objetos aquí protagonistas supone separar unos de otros, cuando ambos podrían implicar una tecnología, una estética y un significado similar. Se podría haber optado, entonces, por incluir estos objetos fuera cual fuese su soporte, siempre que se englobasen en el conjunto de ídolos y objetos suntuosos. Pero ello implicaba otro problema, el desmesurado número de piezas. En cualquier caso, partimos del hueso y el marfil, dejando a un lado otras materias, donde pretendemos ejemplificar la estrecha relación simbólica de los pobladores de Valencina con la fauna y con las materias primas exóticas, como ya apuntan algunos autores ${ }^{65}$.

El interés por la relación entre habitantes y sus recursos naturales está creciendo paulatinamente; por lo que no podíamos dejar pasar la ocasión de recopilar parte de la información de estos materiales en un asentamiento tan paradigmático como es el de Valencina. Así este breve corpus recopilatorio ha querido demostrar, desde una perspectiva más divulgativa, la personalidad que define el entorno cultural de este asentamiento calcolítico, que ha sido reflejo de procesos de cambio ambientales y culturales. Para ello, debemos fijarnos en la abundancia de objetos votivos sobre determinadas materias primas y el surgimiento de unos ídolos antropomorfos masculinos en favor de unos nuevos cambios sociales e ideológicos, cuestionándonos si podría existir o no una diferenciación funcional y, por tanto, simbólica entre los diversos tipos anteriormente descritos. Hasta el momento las interpretaciones sobre estos objetos siguen aludiendo a lo "ritual". Estas hipótesis deberán ser tomadas con cautela y seguir trabajando sobre ellas, para poder dar luz a piezas como los hasta ahora denominados "ídolos sandaliformes" o "sandalias votivas".

Por su parte, los objetos suntuosos parecen tener más peso en este yacimiento, ya que su mayoría posee una naturaleza alóctona en cuanto a su materia prima. Aquí hemos querido cederle el protagonismo al material ebúrneo, ya que los datos relativos a la aparición de marfil asiático y africano en el registro de Valencina durante el III milenio a.n.e, corroboran la interacción cultural y económica en todo el Mediterráneo. Por tanto, resulta evidente la posición excepcional que tuvo este yacimiento en el intercambio de materias primas exóticas dentro de toda la Península Ibérica, ocasionado por su emplazamiento cercano a recursos fluviales y marítimos ${ }^{66}$.

\footnotetext{
${ }^{65}$ Liesau von Lettow-Vorbeck, Corina et al., "La fauna del sector PP4-Montelirio del yacimiento prehistórico de Valencina de la Concepción (Sevilla). Economía y simbolismo de los animales en una comunidad del III milenio", en Menga: Revista de prehistoria de Andalucía, 5 (2014), pp. 69-97.

${ }^{66}$ García Sanjuán, Leonardo, "El asentamiento de..." op. cit., p. 48.
} 
Generalmente localizado en depósitos funerarios -especialmente en Matarrubilla, el PP4-Montelirio y el tholos de Montelirio-, el marfil supone una de las materias primas más abundantes a la hora de contabilizar elementos de ajuar. Posiblemente habrían sido objetos personales, cargados de fuerte significado simbólico otorgado por su naturaleza y ornamentación. Es el caso del puñal de la Estructura 10.042-10.049 o el "pectoral" de cuentas tubulares de Matarrubilla. A estos materiales se les sumarían otros pequeños objetos de índole más naturalista, como las bellotas o las figuras zoomorfas. Posiblemente estas figuras también portaran una interpretación económica, donde la influencia de la gestión animal —especialmente del porcino- y el entorno natural se trasladara a la esfera ideológica de estas comunidades, quedando hoy como una fuente indirecta de conocimiento, como así lo atestiguan los análisis faunísticos.

Estos ornamentos estarían concebidos para ser vistos, de ahí su utilización como objetos simbólicos y suntuosos. Funcionarían como comunicadores, un lenguaje de identidad que, combinado con su materia prima, impregnaría un imaginario colectivo donde sólo unos cuantos serían sus portadores, visible en contextos funerarios. El difunto debía guardar su posición distintiva dentro de la comunidad, por lo que utilizaba estos extraordinarios objetos que posiblemente habría portado en vida —así la combinación de materiales aloctónos dentro de una misma estructura funeraria es bastante común ${ }^{67}$.

De este modo, durante el Calcolítico asistimos al desarrollo de nuevos objetos, de escasa tradición anterior y progresivo aumento en el grado de elaboración; donde el material óseo será para ellos soporte de útiles, adornos, armas e incluso reflejo de creencias y rasgos de identidad, que se integran tanto en la esfera de hábitat como en profundas estructuras de carácter simbólico - como los pozos - y monumentos funerarios. Su representatividad, variedad y valoración nos muestra un camino hacia la especialización artesanal en determinados campos y la creciente jerarquización que desemboca en sistemas sociales complejos, en general, para todo el Suroeste peninsular y especialmente para este enclave andaluz, donde se tendrá que seguir investigando para aportar nuevas teorías que expliquen las muchas cuestiones y planteamientos sobre la estructura social, áreas de ocupación y de producción, además de las simbólicas, que este asentamiento aún plantea.

\footnotetext{
${ }^{67}$ Barciela González, Virginia, Adorno y simbolismo. Los adornos personales en el Neolítico y Eneolítico en Villena (Alicante), Villena, Fundación Municipal José María Soler, 2008.
} 